\title{
Reference genome-assisted identification of stem rust resistance gene Sr62 encoding a tandem kinase
}

\section{Guotai Yu}

John Innes Centre and King Abdullah University of Science and Technology

\section{Oadi Matny}

University of Minnesota

Nicolas Champouret

The Sainsbury Laboratory, University of East Anglia

\section{Burkhard Steuernagel}

John Innes Centre

\section{Matthew J. Moscou}

The Sainsbury Laboratory, University of East Anglia

Inmaculada Hernández-Pinzón

The Sainsbury Laboratory, University of East Anglia

\section{Phon Green}

The Sainsbury Laboratory, University of East Anglia

\section{Sadiye Hayta}

John Innes Centre

Mark Smedley

John Innes Centre

Wendy Harwood

John Innes Centre

Ngonidzashe Kangara

John Innes Centre

Yajuan Yue

John Innes Centre

Catherine Gardener

John Innes Centre

Mark J. Banfield

John Innes Centre

\section{Pablo D. Olivera}

University of Minnesota

\section{Cole Welchin}


University of Minnesota

\section{Jamie Simmons}

University of Minnesota

\section{Eitan Millet}

Tel Aviv University

\section{Anna Minz-Dub}

Tel Aviv University

\section{Moshe Ronen}

Tel Aviv University

\section{Raz Avni}

Tel Aviv University

\section{Amir Sharon}

Tel Aviv University

\section{Mehran Patpour}

Aarhus University

Annemarie F. Justesen

Aarhus University

\section{Murukarthick Jayakodi}

Leibniz Institute of Plant Genetics and Crop Plant Research

\section{Axel Himmelbach}

Leibniz Institute of Plant Genetics and Crop Plant Research

\section{Nils Stein}

Leibniz Institute of Plant Genetics and Crop Plant Research

\section{Shuangye Wu}

Kansas State University

Jesse Poland

Kansas State University

Jennifer Ens

University of Saskatchewan

\section{Curtis Pozniak}

University of Saskatchewan

\section{Miroslava Karafiátová}

Institute of Experimental Botany of the Czech Academy of Sciences

\section{István Molnár}

Institute of Experimental Botany of the Czech Academy of Sciences Jaroslav Doležel

Institute of Experimental Botany of the Czech Academy of Sciences

\section{Eric R. Ward}

The Sainsbury Laboratory, University of East Anglia 


\section{T Lynne Reuber}

2Blades Foundation

Jonathan D. G. Jones

The Sainsbury Laboratory, University of East Anglia

Martin Mascher

Leibniz Institute of Plant Genetics and Crop Plant Research

Brian J. Steffenson ( $\sim$ bsteffen@umn.edu )

University of Minnesota

Brande B. H. Wulff ( $\square$ brande.wulff@kaust.edu.sa )

John Innes Centre and King Abdullah University of Science and Technology

\section{Research Article}

Keywords: Aegilops sharonensis, reference genome, stem rust resistance, Sr62, positional cloning, RNASeq, transformation, tandem kinase, WTK5, broad spectrum resistance

Posted Date: December 29th, 2021

DOI: https://doi.org/10.21203/rs.3.rs-1198968/v1

License: (c) (i) This work is licensed under a Creative Commons Attribution 4.0 International License. Read Full License 


\section{Reference genome-assisted identification of stem rust resistance gene $\mathrm{Sr62}$ encoding a tandem kinase}

Guotai $\mathrm{Yu}^{1,2}$, Oadi Matny ${ }^{3}$, Nicolas Champouret ${ }^{4,15}$, Burkhard Steuernagel ${ }^{1}$, Matthew J. Moscou $^{4}$, Inmaculada Hernández-Pinzón ${ }^{4}$, Phon Green ${ }^{4}$, Sadiye Hayta ${ }^{1}$, Mark Smedley ${ }^{1}$, Wendy Harwood ${ }^{1}$, Ngonidzashe Kangara ${ }^{1}$, Yajuan Yue ${ }^{1}$, Catherine Gardener ${ }^{1}$, Mark J. Banfield $^{1}$, Pablo D. Olivera ${ }^{3}$, Cole Welchin ${ }^{3}$, Jamie Simmons ${ }^{3}$, Eitan Millet ${ }^{5}$, Anna Minz-Dub ${ }^{5}$, Moshe Ronen ${ }^{5}$, Raz Avni ${ }^{5,6,16}$, Amir Sharon 6 , Mehran Patpour ${ }^{7}$, Annemarie F. Justesen ${ }^{7}$, Murukarthick Jayakodi ${ }^{8}$, Axel Himmelbach ${ }^{8}$, Nils Stein ${ }^{8,9}$, Shuangye $\mathrm{Wu}^{10}$, Jesse Poland ${ }^{10}$, Jennifer Ens ${ }^{11}$, Curtis Pozniak ${ }^{11}$, Miroslava Karafiátová ${ }^{12}$, István Molnár ${ }^{12,17}$, Jaroslav Doležel $^{12}$, Eric R. Ward ${ }^{4,13,18}$, T Lynne Reuber ${ }^{13,19}$, Jonathan D. G. Jones ${ }^{4}$, Martin Mascher $^{8,14}$, Brian J. Steffenson ${ }^{3}$ \& Brande B. H. Wulff ${ }^{1,2}$

${ }^{1}$ John Innes Centre, Norwich Research Park, Norwich, NR4 7UH, UK.

${ }^{2}$ Center for Desert Agriculture, Biological and Environmental Science and Engineering Division (BESE), King Abdullah University of Science and Technology (KAUST), Thuwal 23955-6900, Saudi Arabia.

${ }^{3}$ Department of Plant Pathology, University of Minnesota, St. Paul, MN 55108, USA.

${ }^{4}$ The Sainsbury Laboratory, University of East Anglia, Norwich, NR4 7UK, UK.

${ }^{5}$ Institute for Cereal Crops Improvement, Tel Aviv University, Tel Aviv, Israel.

${ }^{6}$ School of Plant Sciences and Food Security, Tel Aviv University, Tel Aviv, Israel.

${ }^{7}$ Department of Agroecology, Aarhus University, Forsøgsvej 1, DK-4200 Slagelse, Denmark.

${ }^{8}$ Leibniz Institute of Plant Genetics and Crop Plant Research (IPK), Seeland, Germany.

${ }^{9}$ Center of integrated Breeding Research (CiBreed), Department of Crop Sciences, Georg-

August-University, Von Siebold Str. 8, 37075 Göttingen, Germany.

${ }^{10}$ Department of Agronomy, Kansas State University, Manhattan, KS 66506, USA.

${ }^{11}$ Crop Development Centre, Department of Plant Sciences, University of Saskatchewan, Saskatoon, SK, Canada.

${ }^{12}$ Institute of Experimental Botany of the Czech Academy of Sciences, Centre of the Region Haná for Biotechnological and Agricultural Research, 77900 Olomouc, Czech Republic.

${ }^{13}$ 2Blades Foundation, Evanston, IL, USA.

${ }^{14}$ German Centre for Integrative Biodiversity Research (iDiv) Halle-Jena-Leipzig, Deutscher Platz 5e, 04103 Leipzig, Germany.

${ }^{15}$ Present address: Ball Horticultural Company, West Chicago, IL 60185, USA.

${ }^{16}$ Present address: Leibniz Institute of Plant Genetics and Crop Plant Research (IPK),

Seeland, Germany.

${ }^{17}$ Present address: Agricultural Institute, Centre for Agricultural Research, ELKH,

Martonvásár, 2462 Hungary.

${ }^{18}$ Present address: AgBiome, Inc., Research Triangle Park, NC 27709, USA.

${ }^{19}$ Present address: Alliance Management at Enko Chem, 62 Maritime Dr, Mystic, CT 06355, USA.

e-mail: brande.wulff@kaust.edu.sa, bsteffen@umn.edu 


\begin{abstract}
The wild relatives and progenitors of wheat have been widely used as sources of disease resistance $(R)$ genes. Molecular identification and characterization of these $R$ genes facilitates their manipulation and tracking in breeding programmes. We developed a reference-quality genome assembly of the wild diploid wheat relative Aegilops sharonensis and used positional mapping, mutagenesis, RNA-Seq and transgenesis to identify the stem rust resistance gene Sr62, which was also transferred to common wheat. This gene encodes a tandem kinase, homologues of which exist across multiple taxa in the plant kingdom.

Stable Sr62 transgenic wheat lines showed high levels of resistance against diverse isolates of the stem rust pathogen, highlighting the utility of Sr62 for deployment as part of a polygenic stack to maximize the durability of stem rust resistance.
\end{abstract}




\section{Introduction}

Stem rust, caused by the fungal pathogen Puccinia graminis f. sp. tritici (Pgt), is one of the most important diseases of wheat worldwide. Stem rust outbreaks were once common, but programs to eradicate the alternate host of this heteroecious fungus, the common barberry (Berberis vulgaris), and breeding for disease-resistant wheat cultivars brought the disease under control across most of Europe and North America by the $1950 \mathrm{~s}^{1}$. Epidemics continued to occur in Australia in the $1970 \mathrm{~s}^{2}$ and South Africa in the $1980 \mathrm{~s}^{3}$. Yet, it was the discovery of stem rust in Uganda in the 1998-1999 growing season on wheat lines carrying Sr31, a widely deployed and, until then, fully effective stem rust resistance gene, which marked a new era in stem rust epidemics ${ }^{4}$. The causal strain popularly known as Ug99 (race TTKSK on the basis of a widely accepted North American differential set of genotypes) and its derivatives subsequently spread throughout most of East and South Africa and into Yemen and Iran and evolved to overcome additional stem rust resistance genes, including Sr24 and $S r 36^{5,6}$. In 2012, a severe outbreak of stem rust not related to the Ug99 lineage occurred in Ethiopia in the widely cultivated wheat cultivar Digalu. The "Digalu" Pgt strain was subsequently detected across the Middle East ${ }^{7}$ and in some European countries, including Sweden, Denmark, Germany and the $\mathrm{UK}^{8,9}$. In 2016 , a stem rust outbreak in southern Italy affected thousands of hectares of both durum and bread wheat ${ }^{10}$, while a separate outbreak in Western Siberia caused $30-40 \%$ yield losses across 1-2 million hectares ${ }^{11}$. Stem rust epiphytotics are predicted to become more common as climate change continues, favouring the northward spread of the fungus ${ }^{12}$. This outlook highlights the importance of developing new wheat varieties with broad-spectrum, durable resistance to stem rust.

So far, 58 distinct stem rust resistance genes have been designated in wheat ${ }^{13}$. Just over half are from bread wheat (Triticum aestivum), while the remainder were introgressed into wheat from wild and domesticated Triticum spp. (eight Sr genes), Aegilops spp. (10 Sr genes), rye (Secale cereale; four Sr genes), wheatgrass (Thinopyrum spp.; four Sr genes) and the grass Dasypyrum villosum (one Sr gene) ${ }^{13}$. Most Sr genes are pathogen- and racespecific, but Sr55/Lr67, Sr57/Lr34 confer slow-rusting multi-pathogen resistance ${ }^{14,15}$. Thirteen of the 58 designated $\operatorname{Sr}$ genes have been cloned, including $\operatorname{Sr} 13^{16}, \operatorname{Sr} 21^{17}, \operatorname{Sr} 22^{18}$, Sr26 ${ }^{19}, \operatorname{Sr} 33^{20}, \operatorname{Sr} 35^{21}, \operatorname{Sr} 45^{18}, \operatorname{Sr} 46^{22}, \operatorname{Sr} 50^{23}, \operatorname{Sr} 55 / L r 67^{14}, \operatorname{Sr} 57 / L r 34^{15}, \operatorname{Sr} 60^{24}$ and Sr6 $1^{19}$. In addition, a race-specific stem rust resistance gene with the temporary designation SrTA1662 was cloned from Aegilops tauschii ${ }^{25}$. Most race-specific Sr genes encode nucleotide-binding and leucine-rich repeat (NLR) proteins, except for $\mathrm{Sr} 60$, which encodes a tandem kinase ${ }^{24}$. The non-pathogen-specific resistance genes Sr57/Lr34 and Sr55/Lr67 encode a putative ATP-binding cassette $(A B C)$ transporter and a hexose transporter, respectively ${ }^{14,15}$.

Five $R$ genes encoding tandem kinases were cloned from various Poaceae species ${ }^{26}$. The first, Rpg1 on chromosome arm $1 \mathrm{HS}$ in barley, confers stem rust resistance ${ }^{27}$. Yr15 on chromosome arm 1BS, originally from emmer wheat (Triticum turgidum ssp. dicoccoides) and subsequently introgressed into bread wheat, confers broad-spectrum stripe rust resistance ${ }^{28}$. Sr60 on chromosome arm 5AS in diploid wheat Triticum monococcum confers race-specific stem rust resistance ${ }^{24}$. Pm24 on chromosome arm 1DS is a powdery mildew resistance gene from the Chinese wheat landrace Hulutou ${ }^{29}$, and the most recent addition, WTK4 on chromosome arm 7DS, confers powdery mildew resistance in Ae. tauschii and synthetic hexaploid wheat derivatives ${ }^{25}$.

Aegilops sharonensis (genome constitution $\mathrm{S}^{\text {sh }} \mathrm{S}^{\text {sh }}$ ) is a wild diploid relative of wheat in the Sitopsis section found in present day Israel and southern Labanon ${ }^{30}$. The species possesses many traits of agricultural importance, including resistance to major diseases of wheat such as the rusts ${ }^{31,32}$. However, the presence of gametocidal genes in the genome of $A e$. sharonensis that restrict interspecies hybridisation have hampered the introgression of its chromatin into wheat ${ }^{33,34,35,36,37}$. Indeed, of all the 264 designated resistance genes that have 
been introgressed into wheat, only three are from Ae. sharonensis, namely Lr56, Yr38 and $S r 62^{13,34}$. Therefore, the genetic potential of $A e$. sharonensis remains largely untapped.

Here, we generated a reference-quality genome assembly of Aegilops sharonensis and cloned the stem rust resistance gene Sr62, earlier designated as Sr1644-1Sh ${ }^{38}$. Sr62 encodes a tandem protein kinase whose individual kinase domain homologues appear across the plant kingdom. Transformation of Sr62 into susceptible wheat cultivar Fielder confirmed the effectiveness of the gene against a range of geographically distinct Pgt isolates. 


\section{Results}

\section{Sequencing and assembly of the Aegilops sharonensis genome}

Ae. sharonensis accession AS_1644 was previously used as the resistant parent in creating a recombinant inbred line population to map the stem rust resistance genes Sr62 (Sr16441Sh) and Sr1644-5Sh and as a donor to introgress these genes into wheat cultivar Zahir ${ }^{37,38}$. To facilitate the cloning and characterisation of these genes, we generated a genome assembly of AS_1644. A line derived from this accession, which had been advanced through two generations of single-seed descent, contained residual heterogeneity of less than one single-nucleotide polymorphism (SNP) per $10 \mathrm{~kb}$ based on analysis of wholegenome shotgun (WGS) reads mapped to 1,440 conserved 'benchmarking universal singlecopy ortholog' (BUSCO) genes. We utilized multiple technologies to sequence this inbred AS_1644 line (Supplementary Fig. 1) and assembled the genome using the TRITEX pipeline $^{39}$. In brief, we performed Illumina sequencing-by-synthesis on WGS short-insert, long mate-pair (LMP), 10X linked read and Hi-C chromatin conformation capture libraries, as well as chromosome flow-sorted short-insert libraries (Supplementary Figure 2;

Supplementary Tables 1 and 2). We derived contig assemblies from the WGS short-insert libraries, scaffolded them sequentially with the LMP and 10X data, and connected them into chromosome pseudomolecules using the Hi-C data.

We obtained a scaffold assembly size of $6.7 \mathrm{~Gb}$ and a scaffold N50 and N90 of 12.3 and 1.1 $\mathrm{Mb}$, respectively (Table 1). The assembly size of the chromosome pseudomolecules is 6.3 $\mathrm{Gb}$, including $886 \mathrm{Mb}$ of unfilled gaps (Table 1). The chromosome sizes range from $783 \mathrm{Mb}$ (chromosome 1) to $1,022 \mathrm{Mb}$ (chromosome 2). Unanchored scaffolds account for $420 \mathrm{Mb}$ (Table 1). To assess the assembly quality, we performed BUSCO analysis. The assembly contains $96.5 \%$ complete BUSCOs and only $1.3 \%$ fragmented and $2.2 \%$ missing BUSCOs (Supplementary Fig. 3). The structural integrity of the pseudomolecules was supported by inter- and intrachromosomal Hi-C contact matrices (Supplementary Figs. 4, 5), its concordance with sequence data from flow-sorted individual chromosomes (Supplementary Fig. 6), and by collinearity with an Ae. sharonensis consensus genetic linkage map comprising 727 sequence markers and spanning $631 \mathrm{cM}^{38}$ (Supplementary Fig. 7).

Sequence comparison with high-confidence genes from the Chinese Spring A-subgenome ${ }^{40}$ identified 29,849 Ae. sharonensis candidate genes ( $84.5 \%$ of the total) at a cut-off of $90 \%$ sequence identity (Supplementary Table 3 ). This increased to 30,260 candidate genes $(88.4 \%)$ after comparison to the D-subgenome and 30,626 (85.9\%) after comparison to the B-subgenome. This analysis suggests that at least 30,626 high-confidence genes are present in our Ae. sharonensis genome assembly. We detected strong collinearity in the distal regions between the Ae. sharonensis and Chinese Spring subgenomes but disrupted collinearity in the centromeric regions (shown for the D-subgenome in Supplementary Fig. 8). 
Table 1 Aegilops sharonensis AS_1644 v 1.0 genome assembly statistics.

\begin{tabular}{|l|r|}
\hline Assembly characteristics & Values \\
\hline Assembly size & $6.7 \mathrm{~Gb}$ \\
\hline *Scaffold N50 & $12.3 \mathrm{Mb}$ \\
\hline *Scaffold N90 & $1.1 \mathrm{Mb}$ \\
\hline Pseudomolecule size & $6.3 \mathrm{~Gb}$ \\
\hline Unfilled gaps & $886 \mathrm{Mb}$ \\
\hline Chromosome $1 S^{\text {sh }}$ & $783 \mathrm{Mb}$ \\
\hline Chromosome 2S & $1022 \mathrm{Mb}$ \\
\hline Chromosome 3S & $972 \mathrm{Mb}$ \\
\hline Chromosome $4 S^{\text {sh }}$ & $827 \mathrm{Mb}$ \\
\hline Chromosome 5S & $868 \mathrm{Mb}$ \\
\hline Chromosome $6 S^{\text {sh }}$ & $807 \mathrm{Mb}$ \\
\hline Chromosome 7S & $1016 \mathrm{Mb}$ \\
\hline Unassigned to a chromosome & $420 \mathrm{Mb}$ \\
\hline Complete BUSCOs & 0.965 \\
\hline Fragmented BUSCOs & 0.013 \\
\hline Missed BUSCOs & 0.022 \\
\hline
\end{tabular}

${ }^{*}$ Scaffolds $<1 \mathrm{~kb}$ were excluded.

\section{Positional mapping of Sr62}

Resistance to stem rust was previously transferred into the wheat cultivar Zahir as a compensating Robertsonian translocation between Ae. sharonensis chromosome $1 S^{\text {sh }}$ and the closely related wheat chromosome $1 \mathrm{BL} / 1 \mathrm{DL}\left(1 \mathrm{~S}^{\text {sh }} \mathrm{S} \cdot 1 \mathrm{~S}^{\text {sh }} \mathrm{L}-1 \mathrm{BL} / 1 \mathrm{~S}^{\text {sh }} \mathrm{S} \cdot 1 \mathrm{~S}^{\text {sh }} \mathrm{L}-1 \mathrm{DL}\right)^{37}$ (Fig. 1a). Independently of this, QTL mapping located Sr62 on the short arm of chromosome $1 S^{\text {sh }}$ in an Ae. sharonensis $\mathrm{F}_{6}$ recombinant inbred line population from a cross between accessions 2189 (susceptible) and 1644 (resistant) ${ }^{38}$. In the same population, a second stem rust resistance locus, Sr1644-5Sh, was localized to the long arm of chromosome $5 S^{\text {sh }}$. To genetically separate these two $\mathrm{Sr}$ loci, we genotyped plants from $\mathrm{F}_{2: 3}$ families and identified one plant, designated 803, that was heterozygous for markers diagnostic for Sr62 on chromosome 1 and homozygous for a marker diagnostic of the susceptible haplotype at Sr1644-5Sh on chromosome 5 (Supplementary Fig. 9a; Supplementary Table 4). We phenotyped and genotyped $49 \mathrm{~F}_{3: 4}$ plants derived from plant 803 and observed a 3:1 segregation ratio for resistance and susceptibility and congruency between resistance and PCR molecular markers diagnostic for accession 1644 on chromosome 1 (Supplementary Fig. 9b; Supplementary Table 4). These results indicated that we had genetically isolated Sr62 and that the gene is dominant in Ae. sharonensis. Furthermore, the markers delimited the position of Sr62 to a 12-cM interval between proximal marker C23635_CAPS and distal marker C25971_CAPS (Supplementary Fig. 9c;Supplementary Tables 5 and 6).

To fine-map Sr62, we developed a large population segregating for $S r 62$ by selfing $F_{4: 5}$ and $F_{5: 6}$ plants derived from plant 803 and heterozygous for the Sr62 interval on chromosome 1. We genotyped 4,638 plants from this population with markers flanking Sr62, revealing 12 recombinants between C11308_KASP and C67147_KASP (Fig. 1b; Supplementary Fig. 9d; Supplementary Table 7). By generating more markers in this interval and phenotyping progeny of the 12 recombinants, we mapped Sr62 to the region between markers 
S741_KASP-7 and C03246_CAPS (Supplementary Table 7), corresponding to a physical interval of $480 \mathrm{~kb}$ on the short arm of Ae. sharonensis chromosome 1 (Fig. 1c).

We performed RNA-Seq on AS_1644 and mapped the reads to the genome assembly. This identified seven transcribed genes in the interval with homology to a remorin family protein, a wall-associated kinase (WAK), two wheat tandem protein kinases (dubbed WTK5 and WTK), an NLR, a 50S ribosomal protein (50S-RP) and a target of Eat1-B1 gene (TOE1-B1) (Fig. 1d).

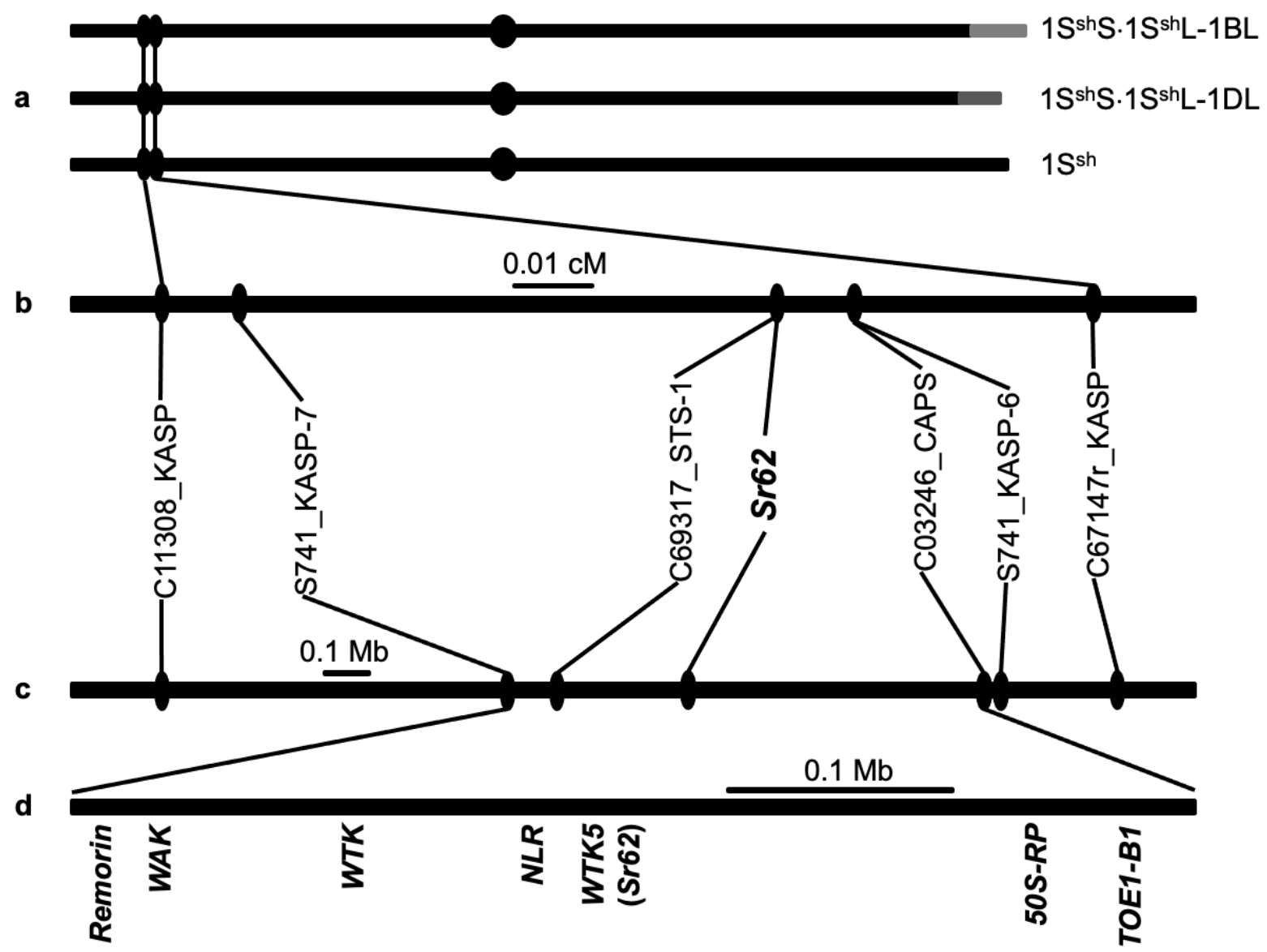

Fig. 1 Positional mapping restricts $S r 62$ to a $480 \mathrm{~kb}$ interval on chromosome $1 \mathrm{~S}^{\text {sh }}$. a, Wheat-Ae. sharonensis translocation chromosomes and Ae. sharonensis chromosome $1 S^{\text {sh }} . \mathbf{b}$, Genetic map of the region harbouring Sr62 on the short arm of Ae. sharonensis chromosome $1 S^{\text {sh }}$. c, Physical map of the region around Sr62. d, Genes in the interval genetically delimiting the presence of Sr62. WTK is presumably an ortholog of $P m 24^{29}$.

\section{Identification of an Sr62 candidate by EMS mutagenesis and RNA-Seq alignment}

To identify Sr62 among the candidate genes in the mapping interval, we performed EMS mutagenesis of Zahir-1644 wheat-Ae. sharonensis introgression lines, in which most of wheat chromosomes $1 \mathrm{D}$ or $1 \mathrm{~B}$ were replaced by chromosome $1 \mathrm{~S}^{\mathrm{sh}}$ of $\mathrm{Ae}$. sharonensis accession $1644^{37}$ (Fig. 1a). We mutagenized 3,025 Zahir-1644 seeds with $0.75 \%$ EMS. Eight or more seeds from the surviving 1,649 $\mathrm{M}_{2}$ families were screened for susceptible mutants using the Pgt isolate Ug99 (race TTKSK). Thirty families segregating for resistance and susceptibility were identified and tested in the $M_{3}$ generation, revealing 14 independent susceptible mutants. Genotyping-by-sequencing ${ }^{41}$ of Zahir, the two Zahir-1644 introgression 
lines and 10 EMS-derived mutants allowed us to rule out cross-contamination from other wheat cultivars for this mutant subset and to determine the translocation type, $1 \mathrm{~S}^{\text {sh }} \mathrm{S} \cdot 1 \mathrm{~S}^{\text {sh }} \mathrm{L}$ $1 \mathrm{BL}$ or $1 \mathrm{~S}^{\text {sh }} \mathrm{S} \cdot 1 \mathrm{~S}^{\text {sh }} \mathrm{L}-1 \mathrm{DL}$ (Supplementary Fig. 10).

We constructed a full-length cDNA library for AS_1644, sequenced this library on the Illumina sequencing platform (generating 98 million 150-bp paired-end reads) and assembled these data to obtain transcripts of the seven genes in the mapping interval. In parallel, we sequenced the leaf transcriptomes of Zahir-1644 and the 14 mutants by generating $\geq 91$ million 150-bp paired-end RNA-Seq reads per sample. We mapped the mutant RNA reads to the transcripts of the seven genes. This procedure, which we termed MutRNA-Seq (Fig. 2), identified eight point-mutations in WTK5 among seven of the 14 mutants. All of the mutations were G/C-to-A/T transition mutations, typical of EMS ${ }^{42}$. We predicted the open reading frame of WTK5 and found that seven of the mutations introduced non-synonymous changes, whereas one introduced an early stop codon (Fig. 3a, b). In contrast, WTK, the NLR, the 50S ribosomal protein and TOE1-B1 had two or no mutations. For the WAK and remorin genes, the expression levels were too low to reliably call mutations (Supplementary Table 8 and 9).

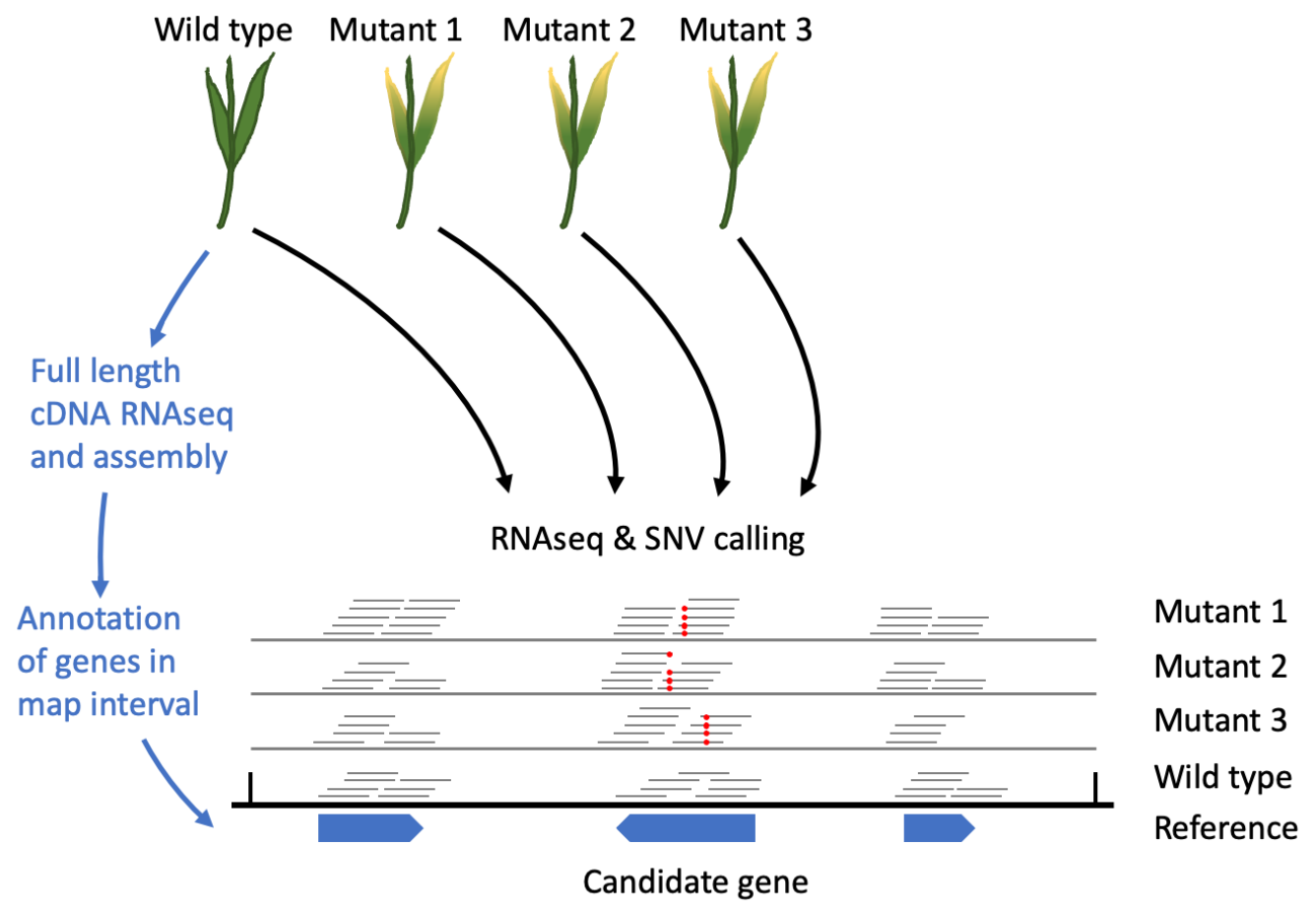

Fig. 2 Candidate gene identification by mutagenesis and transcriptome sequencing (MutRNA-Seq). RNA-Seq reads from the wild-type parent and independently derived EMS mutants are mapped to a reference genome sequence. Annotated genes are inspected (within a mapping interval, if available) for a gene exhibiting a preponderance of singlenucleotide variants (SNVs, red dots) across the mutants.

To test that WTK5 was the candidate among the seven genes, we developed the following formula:

$$
p=1-\left(1-\left(\begin{array}{l}
n \\
k
\end{array}\right)\left(R L_{C}\right)^{k}\left(1-\left(R L_{C}\right)\right)^{n-k}\right)^{\frac{L_{i}}{L_{c}}}
$$

where $p$ is the probability of obtaining $k$ out of $n$ mutants with a mutation in the sequence of at least one of the genes investigated, $n$ is the number of mutants investigated, $k$ is the number of mutants with a mutation in the candidate gene, $R$ is the frequency of EMSinduced mutations in hexaploid wheat $\left(3.11 \times 10^{-5} \text { per } b\right)^{42}, L_{c}$ is the coding DNA sequence 
(CDS) length of the candidate gene (in bp) and $L_{i}$ is the total CDS length of all genes investigated (in bp).

We graphically displayed the minimum number of mutants required to successfully identify a candidate gene by mutational genomics as a function of the number of genes investigated (Supplementary Fig. 11). We considered typical scenarios encountered in mutational genomics studies, such as when scrutinizing all genes in a discrete mapping interval (e.g., ten genes); a whole gene family (e.g., all 3,200 NLR loci in hexaploid wheat ${ }^{43}$ ); a whole chromosome, as obtained by chromosome flow sorting (i.e., 5,100 genes); or all $\sim 107,000$ genes in the hexaploid wheat genome $e^{40}$. This analysis indicated that the minimum number of independent mutants required to identify a candidate gene with a 2,000-bp CDS at $p=0.01$ is $3,5,5$ or 6 , respectively, for the abovementioned scenarios. This increases to $8,16,16$ and 20 mutants, respectively, when dealing with two complementation groups. For our Sr62 mapping interval, which contains seven genes, the probability of obtaining 7 out of 14 mutants with a mutation in the sequence of at least one of the seven genes being investigated based on the WTK5 CDS (2,223 bp) would be $9.0 \times 10^{-5}$. In other words, WTK5 emerged as the best candidate among the seven genes, prompting further functional analysis.

\section{The Sr62 wheat tandem kinase candidate confers stem rust resistance in transgenic wheat}

By mapping the leaf transcriptome RNA-Seq reads to the genome assembly of $A e$. sharonensis, we predicted that the WTK5 transcript spans 18,384 bp and contains 11 introns (Fig. 3a; Supplementary Fig. 12). To engineer a binary construct containing WTK5, primer pairs were designed to amplify two parts of the genomic DNA sequence that cover most of the native gene, including $2.8 \mathrm{~kb}$ of putative promoter sequence $5^{\prime}$ of the predicted start codon and $2.0 \mathrm{~kb}$ of putative terminator region $3^{\prime}$ of the predicted stop codon but excluding $11.4 \mathrm{~kb}$ of the middle of the $12.4-\mathrm{kb}$ intron (Fig. 3a). The two PCR products were separately cloned and combined into a binary vector via three-way ligation: the resulting recombined WTK5 spans $11.9 \mathrm{~kb}$ (Fig. 3c). The construct was verified by Sanger sequencing and transformed into wheat cultivar Fielder. We obtained three independent primary transgenic lines $\left(T_{0}\right)$, which, based on qRT-PCR of the selectable marker, were predicted to contain one copy of the transgene (two lines) or four copies of the transgene (one line). We advanced these hemizygous lines to the next generation to obtain homozygous lines. All three lines conferred resistance to $P g t$ stem rust races TTKSK (isolate Ug99, 04KEN156/04 from Kenya), TKTTF (isolate 13-ETH18-1 from Ethiopia), TKTTF (isolate UK-01 from the UK) and QTHJC (isolate 69MN399 from the US) (Fig. 3d), whereas the null plants were all as susceptible as the parent cv. Fielder (Supplementary Fig. 13). We also tested the line with four copies of the selectable marker against an additional eight Pgt isolates/races from Israel (three isolates), Italy (three isolates), Kenya (one isolate) and Ethiopia (one isolate) and found high levels of resistance (Supplementary Table 10; Supplementary Fig. 14). 
a
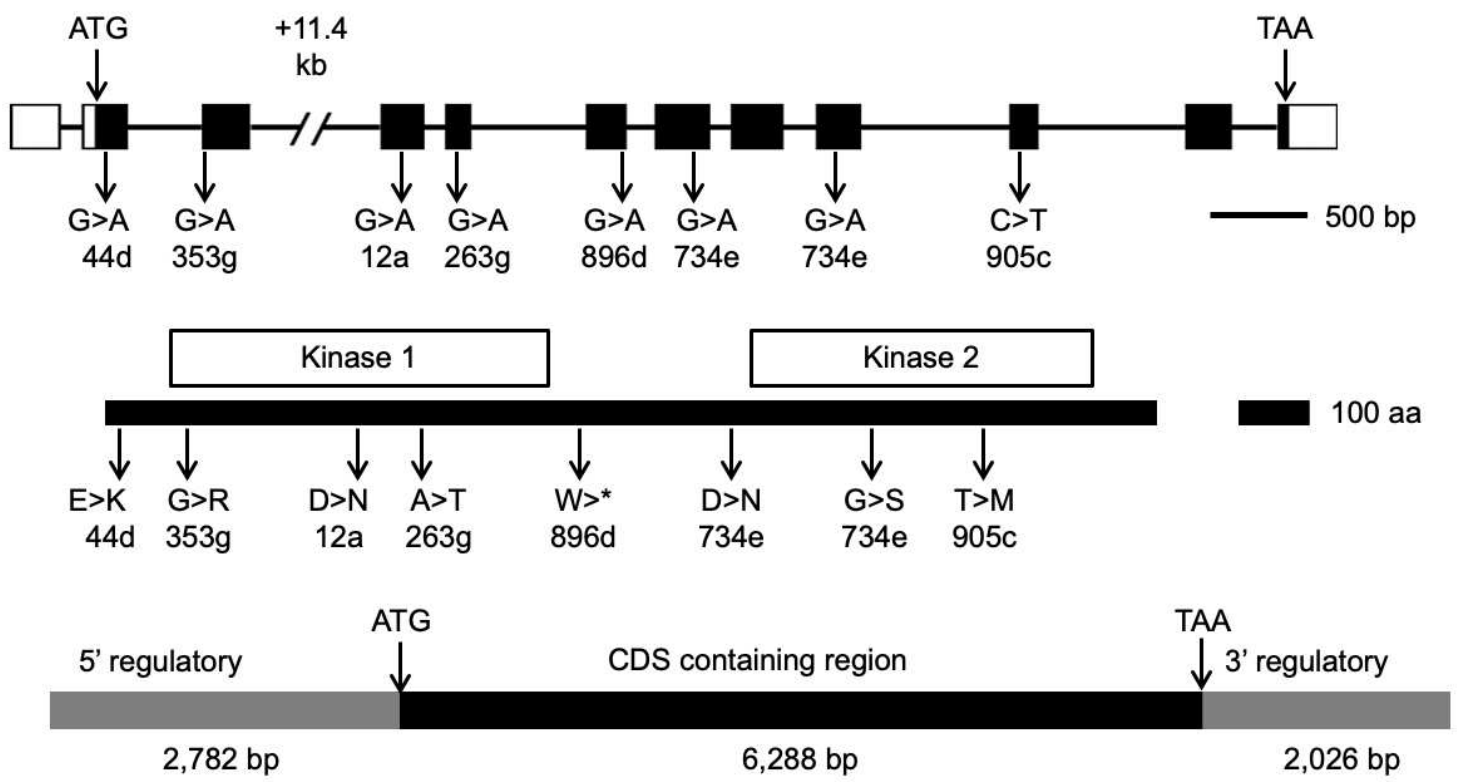

Fig. 3 Functional validation of Sr62 by EMS mutagenesis and transformation into wheat. a, Structure of Sr62, with predicted nucleotide change caused by EMS-derived lossof-function mutations. Boxes represent exons and lines represent introns with white boxes representing untranslated regions and black boxes representing the predicted open reading frame. The 11.4-kb portion of the third intron excluded from the binary construct is indicated. b, Schematic representation of the Sr62 protein, with the position of the two protein kinase domains and the predicted amino-acid changes caused by the EMS mutations indicated. c, The Sr62 sequence used for transformation of wheat cultivar Fielder. CDS, coding DNA sequence. d, Reactions of three homozygous independent transgenic lines to four Pgt isolates. The copy number of the hygromycin selectable marker in $\mathrm{T}_{0}$ plants is indicated.

\section{Both protein kinase domains are required for Sr62 function}

We mapped the mutations in Sr62 relative to the two protein kinase domains. The seven amino acid substitutions are spread evenly throughout the predicted amino acid sequence, with three mutations in the Kinase 1 domain and two in Kinase 2 (Fig. 3b). Moreover, the premature stop codon mutant $896 \mathrm{~d}$ leads to a predicted truncated protein lacking Kinase 2. Based on sequence alignment to previously characterized plant protein kinases, Sr62 is predicted to encode a protein with two serine/threonine kinase domains (Supplementary Fig. 15). In mutant $353 \mathrm{~g}$, a conserved glycine residue at amino acid position 57 was substituted with an arginine proximal to the conserved ATP-binding site of Kinase 1, whereas the aspartic acid-to-asparagine substitution at amino acid position 177 (mutant 12a) is located in the catalytic site of Kinase 1 (Supplementary Tables 11 and 12). Moreover, the substitutions 
at positions 57 and 177 are predicted to be intolerant (Supplementary Table 13). We developed a 3D model of the structure of Sr62 using the Phyre2 web portal ${ }^{44}$ and CCP4MG ${ }^{45}$ and mapped these two amino acid substitutions onto the model. Interestingly, the Aspartate177Asparagine mutation is in a critical residue for kinase function (Supplementary Fig. 16). In active kinases, this Aspartate is involved in binding the phosphate of ATP, and acts as the catalytic residue ${ }^{46}$ functioning as a base acceptor for the proton transfer (Supplementary Fig. 16). The PDB coordinates of the comparative model can be find in the Supplementary file 1 (Sr62_3D_Phyre2.pdb) We searched Sr62 for the presence of eight conserved amino acids that are diagnostic for protein kinases ${ }^{47}$. All eight of these amino acids are found in Kinase 1, whereas five out of the eight are present in Kinase 2. Based on this analysis, Sr62 has a predicted kinase-pseudokinase structure, similar to Pm24. However, our mutant analysis suggests that both protein kinase domains are required for Sr62 function. One of the amino acid substitutions (G539S) in Kinase 2 is predicted to be intolerant (Supplementary Table 13).

\section{Sequence relationship between Sr62 and other tandem kinases in grasses}

To explore the relationship between Sr62 and other tandem kinases in major cereal crop species and wild grasses, we performed phylogenetic analysis of tandem kinases in 11 hexaploid wheat (Triticum aestivum), durum wheat (Triticum durum), barley (Hordeum vulgare), rice (Oryza sativa), sorghum (Sorghum bicolor), maize (Zea mays) and the wild wheat relatives Ae. tauschii and Ae. sharonensis (Fig. 4a). The resistance genes Sr62, Pm24, Rpg1, WTK4 and Yr15 belong to the most populous clade, while Sr60 sits in a small and separate, but closely related, clade (Fig. 4a). The closest neighbour of Sr62 is Pm24, which appears to be a wheat chromosome 1D orthologue of Ae. sharonensis WTK situated $193 \mathrm{~kb}$ away from Sr62 (Fig. 1d). However, the identity between Sr62 and Pm24 is low $(<65 \%)$ at both the CDS and amino-acid sequence levels (Supplementary Table 14). We next generated a phylogenetic tree with the two protein kinase domains from each tandem kinase separated from each other. In this tree, the two domains of Rpg1 and WTK4 are located near each other in Clade 4 (Fig. 4b). By contrast, the two domains of Sr62 and $P m 24$ sit in different clades (Clades 4 and 5), but both Sr62-K2 and Pm24-K2 sit in Clade 4, and both Sr62-K1 and Pm24-K1 sit in Clade 5. The two domains of Sr60 and Yr15 are also in distinct clades (Clades 6 and 7 for Yr15 and Clades 2 and 5 for Sr60). Based on pair-wise alignment using the Needleman-Wunsch method ${ }^{48}$, the two Sr62 kinase domains share $51 \%$ identity. None of the five cloned tandem kinase genes contain kinase domains with more than $80 \%$ nucleotide identity.

Using a Hidden Markov Model-based classification approach for protein kinases developed by Lehti-Shiu \& Shiu ${ }^{49}$, we investigated the individual protein kinase domains in Rpg1, Pm24, Yr15, Sr60, WTK4 and Sr62. Sr62 has a DLSV-DLSV configuration as do Rpg1 and Pm24, whereas the Sr60 protein kinase domains belong to the DLSV (domain 1) and CR4L (domain 2) subfamilies, and the Yr15 domains belong to the WAK (domain 1) and RLCK-VIII (domain 2) subfamilies. 


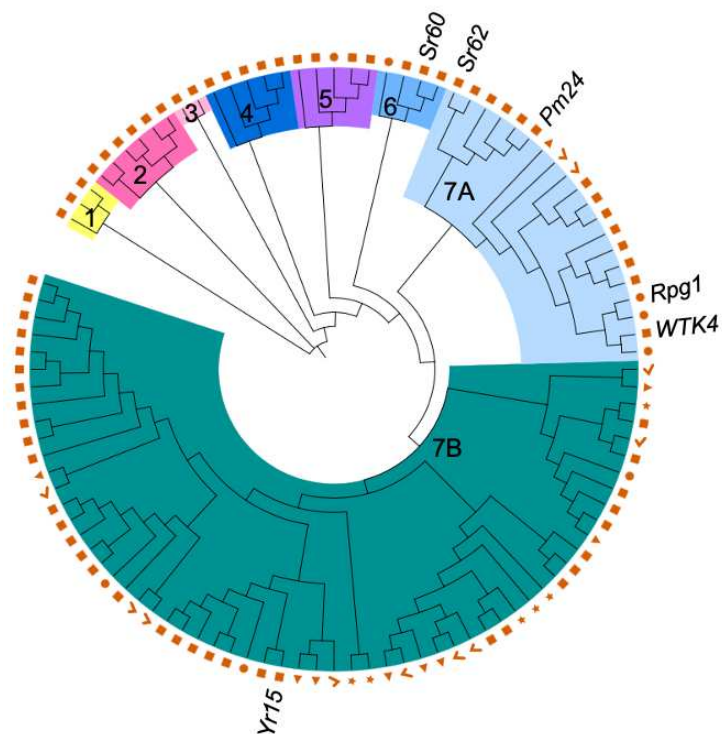

$$
\begin{array}{ll}
\text { Hordeum vulgare } & \text { Oryza sativa } \\
\text { Zea mays } & \checkmark \text { Sorghum bicolor }
\end{array}
$$

$\square$ Triticum aestivum, Triticum durum, Triticum dicoccum, Triticum monococcum, Aegilops sharonensis, Aegilops tauschii

Fig. 4 Phylogenetic relationship between tandem kinases from cereal crop and wild grasses. A total of 99 predicted tandem kinases were retrieved from the genomes of bread wheat, durum wheat, maize, barley, sorghum, rice, Ae. tauschii and Ae. sharonensis, along with the five cloned tandem kinase disease resistance genes. Phylogenetic clades and subclades are indicated by different colours and labelled with numbers. a, Phylogeny based on the whole tandem kinase coding sequence. $\mathbf{b}$, Phylogeny based on the individual protein kinase domain coding sequences.

\section{Sequence homology searches suggest an ancient origin of the individual Sr62 kinase domains, whereas the genome synteny around the gene is specific to closely related grasses}

We performed coding sequence homology analysis of Sr62 using Gramene, a resource for comparative genomics across the plant kingdom ${ }^{50,51}$. Homologues were detected in five phyla: Tracheophyta, Bryophyta, Marchantiophyta, Chlorophyta and Rhodophyta

(Supplementary Table 15). Thus, the homologues of the Sr62 kinase domains are present in species ranging from unicellular green and red algae to mosses, liverworts and crop species including cereals (wheat, barley, rice, maize and sorghum), brassicas, potato, tobacco and coffee. The number of homologues varies widely, from three in the red alga Chondrus crispus to 65 in the wild tobacco Nicotiana attenuata. The Triticum species T. aestivum (hexaploid), T. durum (tetraploid), Triticum dicoccum (tetraploid) and Triticum urartu (diploid) have 26, 34, 19 and 21 homologues, respectively (Supplementary Table 15). These data suggest that the origin of the Sr62 kinase domains predates the diversification of plants.

We conducted synteny analysis extending to ten genes on either side of Sr62 in Ae. sharonensis and compared this region across nine Poaceae genomes spanning 60 million years of evolution ${ }^{52}$. The synteny block contains an F-box protein, a glutamyl-tRNA reductase, a pentatricopeptide repeat-containing protein, a remorin family protein, a protein kinase, an NLR and a TOE1-B1 (Fig. 5). The synteny is well conserved within the Triticum and Aegilops species, and to a lesser extent with barley, where it has undergone extensive rearrangements relative to Triticum and Aegilops. However, the block appears to be absent 
from Brachypodium, rice, sorghum and maize, suggesting that it arose between 11.6 and 35 million years ago $^{52}$ (Fig. 5).
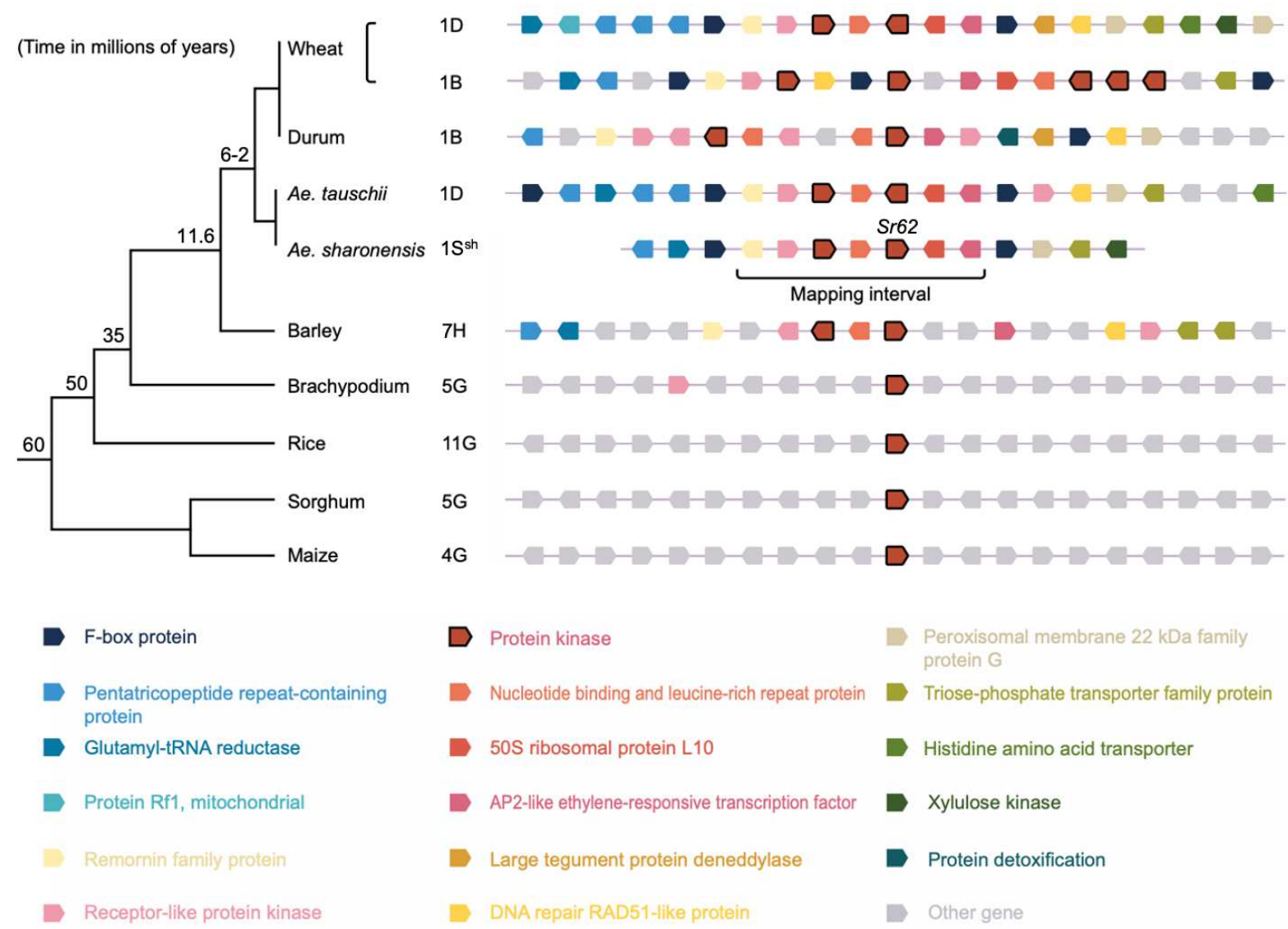

Fig. 5 Synteny around Sr62. Genomic regions containing genes orthologous to Sr62 along with surrounding genes reveal micro-synteny. The syntenic block is well conserved within the Triticum spp., Aegilops spp., and barley, but appears to be absent from Brachypodium, rice, sorghum and maize. The synteny alignment was generated through Gramene, except for Ae. sharonensis which was added manually. 


\section{Discussion}

We cloned the Ae. sharonensis major-effect, dominant stem rust resistance gene Sr62 and found that it encodes a tandem kinase. To date, more than 300 disease resistance genes have been cloned in plants, most of which (189 of 310) contain NLRs ${ }^{53}$. Only a few, from various Poaceae species, encode tandem kinases: Rpg1, Yr15, Pm24, Sr60 and WTK4, all of which were identified in the Triticeae $27,28,29,24,25$. These five genes, as well as Sr62, contain two protein kinase domains. In Rpg1 and WTK4, the two protein kinase domains are close to each other in the same phylogenetic clade (Fig. 4).

Based on sequence conservation of the key amino acid residues for protein kinase function in the two kinase domains, Yr15 and Pm24 have been classified as encoding tandem kinase-pseudokinases, Sr60 as encoding a tandem kinase-kinase and Rpg1 encoding a tandem pseudokinase-kinase gene ${ }^{24}$. Here, based on amino-acid alignment with plant kinases, we identified two absolutely conserved amino acids (residues 57 and 177) in the binding site and catalytic site of Kinase 1 of Sr62 (Supplementary Fig. 16). Two EMSinduced susceptible mutants, $353 \mathrm{~g}$ and $12 \mathrm{a}$, have non-synonymous mutations that alter these two key residues (Supplementary Tables 11 and 12), implying that the function of Kinase 1 of Sr62 is critical for stem rust resistance. Another susceptible mutant (896d) carries an early stop codon resulting in a truncated protein predicted to only contain the Kinase 1 domain, suggesting that an intact Kinase 2 is also required for Sr62 function.

For more than 20 years, the guard model has provided a useful framework for understanding the molecular mechanism and evolution of plant resistance genes ${ }^{54,55}$. According to this model, plant resistance proteins guard the pathogenicity targets (guardees) of pathogen effector molecules. The interaction of an effector with the pathogenicity target is detected by the guard, leading to a conformational change that triggers signalling, resulting in downstream defence responses. In NLR proteins, the C-terminal leucine-rich repeats provide the guarding function, while the $\mathrm{N}$-terminal nucleotide-binding and coiled-coil or TIR domains confer the signalling capacity ${ }^{56,57,58}$. In the absence of a resistance gene, the interaction between guardee and effector protein promotes pathogen growth, resulting in a susceptible phenotype. All three interactors-guard, guardee and effector-are subject to diversifying selection, but for the guardee, this can be constrained by the requirement to maintain cellular function. Duplication of the guardee can release it from this constraint and provide a 'decoy' for the effector ${ }^{59}$. Early experimental support for the guard hypothesis came from the study of Arabidopsis thaliana RIN4, which is guarded by the NLRs RPM1 and RPS 4 and targeted by the bacterial effectors AvrRpm 1 and AvrRpt2 ${ }^{60,61,55,62}$, and tomato Pto, a serine/threonine protein kinase that is guarded by the NLR protein Prf and targeted by the bacterial effector avrPto ${ }^{63,64,55}$. Somewhat unusually, the Pto gene acts genetically as the resistance gene and is part of a complex of six paralogues within a 60-kb region within which Prf is embedded ${ }^{65}$. In A. thaliana, the PBL2 (kinase)-RKS1 (pseudokinase)-ZAR1 (NLR) complex triggers immunity upon detection of the Xanthomonas campestris effector AvrAC ${ }^{66}$.

Perhaps like the Pto protein kinase or the PBL2/RKS1 kinase/pseudokinase, Sr62 is also a pathogenicity target guarded by an NLR. In our EMS mutational genomics experiment targeting Sr62, only seven of 14 susceptible mutants carried non-synonymous or missense mutations in the tandem kinase (Sr62). This suggests that we obtained second-site mutations in one or multiple genes required for Sr62 function. Likewise, EMS mutagenesis of Pm24 (which is syntenic to WTK in the Sr62 haplotype) resulted in 11 mutations in Pm24 out of 26 susceptible mutants ${ }^{29}$. This propensity for second-site mutations is unusual; typically, mutagenesis screens targeting major dominant $R$ genes yield $<20 \%$ second-site suppressors ${ }^{18}$. Identification of the second-site suppressors of Pm24 and Sr62 could provide novel insight into the mechanism of wheat tandem kinase resistance genes. Sr62 and Pm24 both lie adjacent to an NLR gene (Fig. 1). The NLR adjacent to Pm24 did not confer 
powdery mildew resistance when transformed into a susceptible wheat cultivar ${ }^{29}$; however, this does not exclude the possibility that this physically linked NLR is involved in Pm24 function. We identified two EMS mutations in the NLR next to Sr62 (out of the 14 susceptible mutants) of which one was non-synonymous. Further work is required to determine whether the linked NLR functions in concert with the Sr62 and Pm24 tandem kinases in a mechanism similar, for example, to the requirement of tomato Prf (NLR) for Pto function ${ }^{63,64,65}$.

Alternatively, Sr62 could directly perceive the presence of its corresponding effector and activate a downstream signal cascade to confer resistance independent of the involvement of any NLR, as has been proposed for other WTK proteins ${ }^{26}$. In this model, the pseudokinase acts as an effector decoy target that works in concert with the active kinase to initiate defense signaling ${ }^{26}$.

We found that the protein kinase domains in Sr62 belong to the Pelle/DLSV subfamily, which is present in Streptophytes, including angiosperms, gymniosperms, bryophytes, and Steptretophyte algae ${ }^{67}$. The DLSV is highly expanded in angiosperms and is the largest protein kinase family and induced in response to biotic stress in Arabidopsis thaliana ${ }^{67}$. Our working hypothesis is that diverse plant pathogens have evolved effectors that target the DLSV protein kinase family in order to impair immune signaling. A major question is whether the tandem kinases are simply decoys ${ }^{59}$ or have a specific function in immunity (or another process).

To facilitate the practical exploitation of Ae. sharonensis, we developed a high-quality reference genome based on WGS sequencing and chromosome flow sorting. The Ae. sharonensis $\mathrm{N} 50$ scaffold size of $12.3 \mathrm{Mb}$ compares well with those of other assembled Triticeae genomes, including barley (N50, 1.4 Mb) ${ }^{68}$, Ae. tauschii (N50, 11.4 Mb) ${ }^{69}$, durum wheat $(\mathrm{N} 50,6.0 \mathrm{Mb})^{70}$ and bread wheat $(\mathrm{N} 50,22.8 \mathrm{Mb})^{40}$. The assembly contains $96.5 \%$ complete BUSCOs, which is similar to the $95.7 \%$ of rice (Osativa $v 7.0)^{71}$, but higher than the $86.4 \%$ of the first version of the barley reference genome (Hvulgare IBSC_PGSB r1 $)^{72}$.

Using flow cytometry, Eilam et al. determined the nuclear DNA content (1C value) of $\mathrm{Ae}$. sharonensis to be $7.52 \mathrm{pg}^{73}$, which is equivalent to a genome size of $7.35 \mathrm{~Gb}$. We constructed chromosome pseudomolecules covering $6.3 \mathrm{~Gb}$. Compared to the assembled genome sizes of barley $(4.98 \mathrm{~Gb})^{74}$, Ae. tauschii $(4.0 \mathrm{~Gb})^{69}$ and T. urartu $(4.79 \mathrm{~Gb})^{75}$, this is the largest diploid Triticeae genome assembled to date. The $2 \mathrm{~S}^{\text {sh }}$ and $7 \mathrm{~S}^{\text {sh }}$ chromosomes are each physically longer than $1 \mathrm{~Gb}$ (Supplementary Fig. 5). Interestingly, the short arm of $7 S^{\text {sh }}$ (as defined by synteny to other Triticeae) appears to be physically longer than the long arm (Supplementary Fig. 5).

The D-subgenome of hexaploid wheat had a slightly higher percentage of high-confidence genes that aligned with Ae. sharonensis (88.4\%) than the A- and B-subgenomes $(84.5 \%$ and $85.9 \%$, respectively; Supplementary Table 3). This supports a closer relationship between Ae. sharonensis and the D-subgenome, as previously reported based on gene tree topologies ${ }^{76,77}$. Further supporting this close evolutionary relationship, extensive haplotype collinearities were observed between Ae. sharonensis and wheat D-subgenome chromosomes $^{78}$. Therefore, future Ae. sharonensis introgressions into wheat should be directed to the D-subgenome to reduce the likelihood of genetic imbalance. However, gametocidal genes in Ae. sharonensis make it difficult to develop introgression lines for every chromosome ${ }^{79,37}$. Our Ae. sharonensis reference genome will support ongoing efforts to clone these gametocidal genes ${ }^{80,35,81}$, perhaps leading to tools for accelerating introgression of Ae. sharonensis chromatin into wheat. However, because of the hybridization barrier imposed by the gametocidal genes themselves, Ae. sharonensis remains a largely unexploited source of resistance to major diseases of wheat ${ }^{30}$. The reference genome presented here will aid in the molecular cloning of such resistance genes, allowing their incorporation into genetically modified (GM) polygene stacks. 
Several recently developed technologies facilitate the cloning of disease resistance genes in plants ${ }^{13}$. NLR or WGS sequencing combined with association mapping have been successfully applied for the rapid cloning of Sr46, SrTA1662 and WTK4 in Ae. tauschii ${ }^{22,25}$. Mutagenesis combined with NLR sequencing (MutRenSeq) or chromosome sequencing (MutChromSeq) allowed the rapid cloning of the wheat resistance genes Sr22, Sr26, Sr45, Sr61, Yr5a, Yr5b, Yr7 and Pm2 and the barley gene Rph1 18,82,83,19. Mutagenesis combined with mapping, chromosome flow sorting and de novo generation of a cultivar-specific reference-quality single-chromosome assembly facilitated the cloning of $L r 22 a$ and $P m 21^{84,85}$. Here we used a combination of whole-genome de novo assembly, positional mapping and RNA sequencing of multiple EMS-derived mutants to clone Sr62. The newly assembled reference genome of $A e$. sharonensis facilitated fine mapping without BAC libraries to delimit Sr62 to a 480-kb interval based on screening 9,276 products of meiosis. We identified seven genes in the interval with homology to a remorin, WAK, WTK, NLR, WTK5, 50S and TOE1-B1 gene. By applying RNA-Seq to 14 EMS-derived mutants, we identified WTK5 as the best candidate. The transformation of Sr62 into cv. Fielder confirmed that Sr62 is sufficient to confer resistance to stem rust, indicating that MutRNA-Seq is a powerful tool for gene identification.

The effectiveness of mutational genomics approaches, including MutRenSeq ${ }^{18,19}$ and the MutRNA-Seq method developed in this study, relies on multiple factors, including (i) the number of genes controlling a phenotype, (ii) the delimitation of the target gene to a physical map interval, chromosome or gene family and (iii) the number of mutants obtained. To aid in the future experimental design of mutational genomics studies in hexaploid wheat, we calculated the minimum number of mutants required to confidently (at $p=0.01$ ) identify the correct gene. When considering a discrete map interval, a gene family, a whole chromosome or indeed all the genes in the wheat genome, this ranges from three to six mutants, but it increases to eight to 20 mutants if two complementation groups are revealed by mutagenesis (Supplementary Fig. 11). In practice, most gene cloning studies require a combination of genetic mapping with gene knockout and/or gain-of-function experiments. Extending MutRNA-Seq to other plant species requires sexual reproduction and the ability to obtain mutants. Obtaining mutants is favoured by an agronomy that promotes a large seed set and facile plant husbandry. Polyploidy can also be considered an advantage. This makes it easier to achieve an effective mutagen dose without killing the emerging seedlings or causing sterility. In addition, polyploid plants typically tolerate a 4-fold higher mutation density compared to diploids ${ }^{42}$, which reduces the size of the population that needs screening.

Advances in genomics and bioinformatics, such as those described here, are fuelling an exponential growth in the discovery and cloning of disease resistance genes in wheat and its wild relatives ${ }^{13}$. This is providing exciting opportunities for engineering broad-spectrum and durable disease resistance into wheat. The current major obstacle is no longer technical but imposed by the socio-political stalemate on the acceptance of GM wheat ${ }^{86}$. However, in May 2021 the Argentine biotechnology company Bioceres Crop Solutions and the Latin American food production and high street franchise Havanna announced the marketing of Alfajores biscuits made from a GM wheat containing the hahb-4 gene from sunflower conferring drought tolerance ${ }^{87}$. In November of the same year, the Brazilian National Biosafety Commission announced the approval of flour made from hahb-4 wheat ${ }^{88}$. Hopefully this and other efforts will lower the barrier for introducing other GM traits into wheat, such as for disease resistance. 


\section{Methods}

\section{Phenotyping}

The Ae. sharonensis panel was phenotyped for stem rust resistance as previously described $^{38}$. The infection types (IT) were recorded using the Stakman scale ${ }^{89}$.

\section{DNA extraction and sequencing}

Leaf tissue from a single plant of Ae. sharonensis accession 1644 (line number BW_24933) was collected at the 7-leaf stage, and the DNA was extracted using the CTAB method for large quantities of DNA ${ }^{90}$. PCR-free short insert libraries (450 bp and $800 \mathrm{bp}$ ) and long mate pair (MP) (3 kb and $6 \mathrm{~kb}$ ) libraries were generated and sequenced at Novogene, while the 9 $\mathrm{kb}$ long MP library was generated and sequenced at the Roy J. Carver Biotechnology Center, University of Illinois.

DNA for Hi-C and 10X was extracted as outlined in Jupe et al ${ }^{91}$. Briefly, nuclei were extracted from up to $1 \mathrm{~g}$ of fresh leaf tissue by homogenization in $10 \mathrm{ml}$ of nuclei isolation buffer, filtered through cell strainers and separated from debris using a Percoll layer. The extracted nuclei were embedded in low-melting agarose plugs and exposed to lysis buffer with proteinase $\mathrm{K}$ and RNase $\mathrm{A}$. DNA was released by digesting the agarose with Agarase enzyme (New England Biolabs, Ipswich, MA, USA) and analysed by pulsed-field gel electrophoresis.

High-molecular-weight (HMW) genomic DNA (>40 kb) was isolated from the agarose plugs using pulsed-field electrophoresis on a Blue Pippin instrument (Sage Science) following the high-pass protocol with minor modifications. The size and integrity of the recovered HMW DNA was evaluated on a Tapestation 2200 (Agilent) and quantified by fluorometry (Qubit 2.0). One $10 \mathrm{X}$ sequencing library was prepared following the Chromium Genome library protocol v2 (10X Genomics) and sequenced across two lanes of HiSeqX with 150-bp pairedend $(P E)$ reads (Illumina), which produced $\sim 827$ million reads $(\sim 33 \times$ coverage). Long Ranger (10X Genomics) was used to generate FASTQ files for analysis.

\section{Flow cytometric analysis and sorting}

Suspensions of mitotic metaphase chromosomes were prepared from root tips of Ae. sharonensis accession 1644 as described by Vrána et al ${ }^{92}$ and Kubaláková et al ${ }^{93}$. Briefly, root tip meristem cells were synchronized using hydroxyurea, accumulated in metaphase using amiprohos-methyl and mildly fixed in formaldehyde. Intact chromosomes were released by mechanical homogenization of 100 root tips in $600 \mu \mathrm{l}$ ice-cold LB01 buffer. Microsatellites GAA and ACG were labelled on isolated chromosomes by fluorescence in situ hybridization in suspension (FISHIS) using 5'-FITC-GAA7-FITC-3' and 5'-FITC-ACG7FITC-3' oligonucleotides (Sigma, Saint Louis, USA) according to Giorgi et al. (2013), and chromosomal DNA was stained by DAPI (4',6-diamidino 2-phenylindole) at $2 \mu \mathrm{g} / \mathrm{ml}$.

Chromosome analysis and sorting were performed using a FACSAria II SORP flow cytometer and sorter (Becton Dickinson Immunocytometry Systems, San Jose, USA). Bivariate flow karyotypes FITC vs. DAPI fluorescence were acquired for each sample, and chromosomes were sorted at a rate of 1,500-2,000 particles per second. Two batches of 25,000-76,000 copies of each chromosome (chromosomes 1Sh and 6Sh were sorted together) were sorted into PCR tubes containing $40 \mu \mathrm{l}$ sterile deionized water.

The chromosome contents of flow-sorted fractions were estimated by microscopic observation of 1,500-2,000 chromosomes sorted into a 10- $\mu$ l drop of PRINS buffer containing $2.5 \%$ sucrose $^{94}$ on a microscopic slide. Air-dried chromosomes were labelled by FISH with probes for $\mathrm{pSc} 119.2$ repeat, GAAn microsatellite and 45S rDNA according to Molnár et $\mathrm{al}^{95}$. At least 100 chromosomes were classified following the karyotype described 
by Zhang et $\mathrm{al}^{96}$ and Badaeva et $\mathrm{al}^{97}$ to determine the chromosome content of flow-sorted samples and to assign the populations observed on bivariate flow karyotypes to particular chromosomes.

Flow-sorted chromosome samples were treated with proteinase $\mathrm{K}$, after which their DNA was purified and amplified by multiple displacement amplification (MDA) using an Illustra GenomiPhi V2 DNA Amplification Kit (GE Healthcare, Chalfont St. Giles, United Kingdom) as described by Šimková et $\mathrm{al}^{98}$.

\section{Genome assembly}

Chromosome-scale sequence assembly was performed using the TRITEX assembly pipeline as described by Monat et al ${ }^{39}$. Libraries containing a $\sim 450$-bp insert size and sequenced with 250-bp paired-end reads (PE450 libraries) were merged with BBMerge ${ }^{99}$ and error-corrected with BFC ${ }^{100}$. Corrected libraries were used for iterative assembly with Minia3 (k-mer sizes: 100, 200, 250, 300, 350, 400, 450) ${ }^{101}$. Assembled unitigs were scaffolded with PE800, MP3, MP6 and MP9 data using SOAPDenovo ${ }^{101}$. Internal gaps in scaffolds were closed with GapCloser ${ }^{102}$. Chromosome-scale sequence scaffolds (pseudomolecules) were constructed with R scripts of the TRITEX pipeline using linkage information afforded by $10 \mathrm{X}$ linked-reads, Hi-C data, flow-sorting data and a genetic map ${ }^{38}$. As the genetic map of Ae. sharonensis was less dense than the POPSEQ maps of bread wheat ${ }^{103}$ and barley ${ }^{104}$, we modified the TRITEX workflow by adopting an iterative approach for pseudomolecule construction. In the first iteration, scaffolds were assigned to chromosomes using the $\mathrm{Hi}-\mathrm{C}$ map and the genetic map as a guide. $\mathrm{Hi}-\mathrm{C}$ data were then used to order scaffolds within chromosomes so that approximate chromosomal locations for most scaffolds were known. In the second iteration, this ordering of scaffolds was used to guide the construction of super-scaffolds with $10 \mathrm{X}$ linked reads, accepting only scaffold joins supported by both $10 \mathrm{X}$ reads and proximity in the Hi-C map. The $10 \mathrm{X}$ super-scaffolds were ordered along the chromosomes with $\mathrm{Hi}-\mathrm{C}$ data. Flow-sorting data were used to corroborate $\mathrm{Hi}-\mathrm{C}$-based chromosome assignments and to correct errors. Finally, manual correction of chimeric scaffolds and refinements to the order and orientation were performed by visual inspection of $\mathrm{Hi}-\mathrm{C}$ contact matrices.

\section{Initial Sr62 mapping with $\mathbf{8 0 3}$ family}

We developed several $F_{3: 4}$ families from the cross between accession 2189 (susceptible) and accession 1644 (resistant) (Yu et al., 2017) by single-seed descent. One of these families, 803, segregated 3 resistant to 1 susceptible plant. Using this family, we developed a linkage map for Sr62 and using 192 plants, delimited Sr62 to between CAPS markers C24499_CAPS and C23635_CAPS (Supplementary Fig. 9).

Preliminary mapping was performed using genetic markers developed from the $A e$. sharonensis 1644 genome that was based on $1.15 \mathrm{e} 9$ Illumina 100 bp paired-end reads ${ }^{76}$. WGS of $A$ e. sharonensis 2189 (7.6e8 Illumina 100 bp paired-end reads) were aligned to the Ae. sharonensis 1644 genome using BWA (BWA 0.7.17). Single nucleotide variations were identified using bcftools and filtered using vcfutils.pl. False positive SNPs were minimized based on variations identified with self-alignment of Ae. sharonensis 1644 reads. A total of $2,608,758$ SNPs were identified based on filtering for positions with unambiguous read support (i.e. homozygous variations). Using the barley consensus genetic map ${ }^{105}$, putative orthologs were identified in the Ae. sharonensis 1644 genome and SNVs selected for the development of Sequenom assays. Putative single nucleotide polymorphisms between Ae. sharonensis accessions 1644 and 2189 were extracted with 80 bp flanking sequence.

These sequences were used as templates for primer design using MassARRAY software v3.1 for the multiplexing of two 28 SNP assays (a total of 56 SNP assays). Sequenom genotyping was carried out at the lowa State University Genomic Technologies Facility 
(Ames, IA, USA). All SNPs and WGS contig source information for Sequenom markers are detailed in Supplementary Table 5.

\section{High-resolution mapping of Sr62}

We first screened 1,304 plants (2608 gametes) from the 803 family and identified 47 recombinants between the two flanking markers C24499_SBE and C23635_CAPS. These were restricted to six key recombinants with the STS marker C11837_CAPS. When the whole-genome shotgun sequencing and assembly became available, KASP (https://www.biosearchtech.com/Supplementaryport/education/kasp-genotypingreagents/how-does-kasp-work) markers were developed by identifying SNPs between the genomic scaffold sequences of 1644 and those of the susceptible parent $2189^{38}$. Two of these markers, C122784_KASP and C2468909_KASP, were used to screen the progeny of 3,342 plants (6684 gametes) derived from heterozygous 803 family individuals. All markers (Supplementary Table 6) were designed using Primer3 Input (http://bioinfo.ut.ee/primer3$\underline{0.4 \cdot 0 /)}$.

\section{RNA extraction and Sr62 annotation}

Total RNA was extracted from Ae. sharonensis accession 1644 with an RNeasy Plant Mini Kit (Cat No./ID: 74904, Qiagen, Valencia, CA, USA) following the manufacturer's protocol and digested with DNase (Roche). RNA-Seq was performed by Novogene. The RNA-Seq reads were trimmed with Trimmomatic (http://www. usadellab.org/cms/?page=trimmomatic). Hisat2 ${ }^{106}$ (version 2.1.0) was used to map the short reads onto the Sr62 reference sequence. The SAM output file was converted into a BAM file using SAMtools ${ }^{107}$ (version 1.8) (http://www.htslib.org/) and sorted according to their position in the reference and indexed for visualization by IGV (https://software.broadinstitute.org/software/igv/). The fulllength cDNA library was constructed using SMARTer® PCR cDNA Synthesis kit (Cat. \# 634926, Clontech/TaKaRa) and sequenced on Illumina platform. The sequence reads were assembled using clc program (https://digitalinsights.qiagen.com/productsoverview/discovery-insights-portfolio/analysis-and-visualization/qiagen-clc-assembly-cell/)

\section{Mutant development}

To further determine the candidate gene for Sr62, we mutagenized 3,025 seeds of an introgression line containing Sr62 derived from Ae. sharonensis accession 1644 in the hexaploid bread wheat ( $T$. aestivum) cultivar Zahir background (Zahir-1644) $)^{37}$. Dry seeds were treated for $16 \mathrm{~h}$ with $200 \mathrm{ml}$ of $0.75 \%$ EMS solution while being rolled on a Roller Mixer (Model SRT1, Stuart Scientific) to ensure maximum homogenous exposure of the seeds to the EMS. The excess solution was then removed, and the seeds were washed three times with $400 \mathrm{ml}$ tap water. The $M_{1}$ seeds were grown in the greenhouse, and the seeds of $M_{2}$ families (single heads) were collected. Eight seeds per family were phenotyped with Pgt isolate 04KEN156/04 (Ug99), race TTKSK. The $M_{3}$ seeds derived from susceptible $M_{2}$ plants were also tested to confirm that the $\mathrm{M}_{2}$ susceptible plants were true mutants. To rule out seed contamination a subset of the mutants was verified using genotyping-by-sequencing $(\mathrm{GBS})^{108}$.

GBS data from the background (Zahir), donor (Ae. sharonensis, accession 1644) and introgression lines were mapped to the reference sequence of Chinese Spring ${ }^{40}$ using BWA mem (version 0.7.12) with standard parameters ${ }^{109}$. Mappings were sorted and converted to mpileup format using SAMtools ${ }^{107}$ (version 0.1.19). The mpileup files were examined with a custom script to calculate the percentage of SNPs from the donor that were shared with the introgression line per given interval. Several interval lengths were tested; a clear signal was observed for $10 \mathrm{Mb}$.

\section{RNA mapping}


Fourteen susceptible mutants derived from independent $\mathrm{M}_{2}$ families were selected for RNAseq. Total RNA was extracted from 14-day-old seedlings of the susceptible mutants and the wild-type Zahir-1644 parent line. The raw reads from the 14 mutants were mapped to the CDS of the seven genes from the Sr62 map interval using BWA ${ }^{109}$ (version 0.7.12) and SAMtools ${ }^{107}$ (version 1.8). One CDS in the interval was identified as having a single nucleotide mutation in seven of the 14 mutants (Supplementary Table 8). All identified mutations were G-to-A or C-to-T transition mutations, which are typical of EMS mutagenesis. The coverage of the remaining two genes (remorin and WAK) was too low to call mutations (Supplementary Table 8). RPK and TPM were calculated by BLASTing FASTA files converted from the assorted BAM files ${ }^{107}$ with the CDSs. The amino acid substitution tolerance / intolerance was analysed with THE web-based program SIFT ${ }^{110}$ (https://sift.bii.astar.edu.sg/www/SIFT_seq_submit2.html)

\section{Formula development}

We assume that there are $n$ mutants in total and that $k$ mutants have a mutation in the candidate gene CDS. The CDS length (in bp) is $L_{\mathrm{c}}$ and the mutation rate is $R$, and therefore the probability that the candidate CDS is present in a single mutant is $R L_{c}$. Thus, the probability $\left(p_{c}\right)$ for the event, where $k$ out of $n$ mutants have a mutation in the candidate CDS, is a binomial distribution ${ }^{111}$, expressed as:

$p_{C}=\left(\begin{array}{l}n \\ k\end{array}\right)\left(R L_{C}\right)^{k}\left(1-\left(R L_{C}\right)\right)^{n-k}$

If there were $m$ genes being investigated (such as those in the genetic mapping interval of positional cloning) and their CDS were the same length as the CDS of the candidate gene, the probability $(p)$ that the event occurs at one or more of the genes being investigated would be:

$p=1-(1-p c)^{m}$

Because CDS lengths vary among genes, it is necessary to introduce the concept of the effective number $\left(m_{e}\right)$. The effective number of the gene's CDS relative to the candidate gene's CDS is the total CDS length $\left(L_{i}\right)$ of the genes divided by the length $\left(L_{c}\right)$ of the candidate gene CDS.

$m_{e}=\frac{L_{i}}{L_{C}}$

Therefore, the probability of obtaining $k$ out of $n$ mutants with a mutation in the sequence of at least one of the genes being investigated is:

$$
p=1-\left(1-\left(\begin{array}{l}
n \\
k
\end{array}\right)\left(R L_{C}\right)^{k}\left(1-\left(R L_{C}\right)\right)^{n-k}\right)^{\frac{L_{i}}{L_{C}}}
$$

The CDS of most cloned plant disease resistance genes are $\sim 2,000$ bp long ${ }^{24,25,27,28,29}$, while the average CDS length in wheat is $1,000 \mathrm{bp}^{75}$. The probabilities displayed in

Supplementary Fig. 11 were calculated based on the following assumptions: (i) the candidate gene has a 2,000-bp CDS, (ii) every NLR has a 2,000-bp CDS, (iii) the average CDS length of a gene on one chromosome or throughout the genome is $1,000 \mathrm{bp}$, (iv) all mutants are assumed to have a mutation where the trait is controlled by one gene, and half of the mutants have a mutation where the trait is controlled by two genes. The probability for any candidate gene can be calculated given the specific genome mutation rate, candidate gene CDS length, total number of mutants, number of mutants with mutation in the CDS, and effective number of genes being investigated. In practice, the effective number can be approximated based on total number of genes being investigated by multiplying the average length $\left(L_{a}\right)$ of the gene CDS and then dividing by the candidate-gene CDS length.

$$
m_{e}=\frac{m L_{a}}{L_{c}}
$$




\section{Engineering Sr62 binary construct}

The 5' and 3' halves of Sr62 containing 2,782 bp of the putative promoter and 2,026 bp of the putative terminator sequence, respectively, were PCR-amplified so as to leave out 11.4 $\mathrm{kb}$ of the third intron (Fig. 3a). The amplification was made with the high fidelity Q5 DNA polymerase (NEB, Ipswich, MA, USA) following the manufacturer's instructions. The PCR products were purified with QIAquick PCR Purification kit (QIAGEN, LLC, Germantown, MD 20874, USA). The purified fragments were tailed with nucleotide A using Taq DNA polymerase and cloned into the pCR2.1 vector (TOPO PCR Cloning Kits-K202020, Thermo Fisher Scientific). The positive clones were multiplied and the plasmid DNAs were digested with two pairs of restriction enzymes, Notl + EcoRI (NEB, Ipswich, MA, USA) for the 5' fragment and EcoRI + Pmel (NEB, Ipswich, MA, USA) for the 3' fragment. The two digested fragments were gel purified and then ligated into the binary vector pGGG-AH-Notl/Pmel ${ }^{112}$ linearized with Notl and Pmel in a three-way ligation using T4 ligase (M0202S, NEB, Ipswich, MA, USA). A positive clone, pGGG-Sr62, was bulked and verified by Sanger sequencing. pGGG-Sr62 is available from Addgene under the name pGGG-Sr1644-1Sh, accession number 164087.

\section{Wheat transformation}

The binary construct pGGG-Sr62 was used in Agrobacterium-mediated transformation of wheat cv. Fielder as described by Hayta et al. ${ }^{112}$. The copy number of the hygromycin selectable marker (as a proxy for the Sr62 copy number) in $T_{0}$ and $T_{1}$ plants was determined by iDNA Genetics (Norwich, UK) using qPCR, as described in Bartlett et al. ${ }^{113}$.

\section{Evaluation of resistance to stem rust in transgenic wheat seedlings}

The primary transgenic plants $\left(T_{0}\right)$ were tested for stem rust response with the UK-01 isolate ${ }^{9}$ and $T_{1}$ plants were further tested with multiples isolates/races including TTKSK (isolate Ug99, 04KEN156/04 from Kenya), TKTTF (isolate 13-ETH18-1 from Ethiopia), TKTTF (isolate UK-01 from the United Kingdom), QTHJC (isolate 69MN399 from the USA), TKTSC (isolate \#2079 from Israel), TTTTF (isolate \#2127 from Israel), TTTTC (isolate \#2135 from Israel), TTKTT (isolate KE184a/18, from Kenya), TKTTF (isolate ET11a/18, from Ethiopia), TKKTF (isolate, IT200a/18, from Italy), and TTRTF (isolate IT16a/18, from Italy) (Supplementary Table 10).

\section{Homology searching}

BLAST analysis against TGAC CS42 v1 gene models was performed using the Sr62 CDS as a query (http://v0561/blast.html). The best hit (TRIAE_CS42_1BS_TGACv1_050726_AA0174710.1) was used for homology searching using Gramene, a comparative resource for plants $^{50,51}$ ( http://www.gramene.org/\#\%7B\%22filters\%22:\%7B\%22text:TRIAE CS42 1BS T GACv1 050726 AA0174710.1\%22:\%7B\%22category\%22:\%22Gene \%22,\%22display nam e\%22:\%22All\%20genes\%20that \%20contain \%20the\%20word \%20\%5C\%22TRIAE CS42 1 BS TGACv1 050726 AA0174710.1\%5C $\% 22 \% 22, \% 22 \mathrm{fq} \% 22: \% 22 \mathrm{text}:$ TRIAE CS42 1BS TGACv1 050726 AA0174710.1\%22,\%22exclude\%22:false \%7D \%7D, \%22taxa\%22:\%7B\%7 D\%7D). The taxonomy for selected species/subspecies was retrieved from Taxonomy Browser (https://www.ncbi.nlm.nih.gov/Taxonomy/Browser/wwwtax.cgi?id=1437183). The taxonomy was organized by Kingdom, Phylum, class, order and species. Each selected species was blasted with the Sr62 protein sequence or CDS at the NCBI webpage (https://blast.ncbi.nlm.nih.gov/Blast.cgi).

\section{Phylogenetic analysis of plant protein kinase domains}

The CDS of the putative protein kinase genes previously extracted from the wheat cv. Chinese Spring reference genome (IWGSC, 2018) for phylogenetic analysis of $\mathrm{Yr}^{2} 5^{28}$ were used as queries for BLAST analysis against the Chinese Spring, durum, barley, rice, sorghum and maize genomes (http://plants.ensembl.org/index.html). For T. monococcum, $T$. 
dicoccum, Ae. tauschii and Ae. sharonensis, only the cloned gene sequences were added to the phylogenetic trees. The sequence of the Sr62 tandem kinase was determined based on the BLAST results with the CDS

(https://blast.ncbi.nlm.nih.gov/Blast.cgi?PROGRAM=blastx\&PAGE TYPE=BlastSearch\&LIN $\mathrm{K}$ LOC=blasthome, non-redundant protein sequence-nr). The retrieved CDS were used to perform BLAST analysis against the NCBI protein database

(https://blast.ncbi.nlm.nih.gov/Blast.cgi?PROGRAM=blastx\&PAGE TYPE=BlastSearch\&LIN $\mathrm{K}$ LOC=blasthome, non-redundant protein sequence-nr) and manually checked for the kinase domain. Genes with two or three complete protein kinase domains were selected for phylogenetic analysis. A total of 105 genes were used for analysis: 51 from Chinese Spring, 15 from durum, seven from barley, six from rice, 11 from sorghum, nine from maize and the six cloned Poaceae genes previously discussed (including Sr62). For kinase domain analysis, all 105 tandem kinase sequences were split into two or three kinase domain sequences and were used for phylogenetic analysis based on domain sequences. A phylogenetic tree (neighbour-joining tree) for whole genes and domains was computed with Clustal Omega (https://www.ebi.ac.uk/Tools/msa/clustalo/) and drawn with iTOL (https://itol.embl.de/). Hidden Markov Model classification was performed using hmmscan (v3.1b2). HMMs were obtained from the supplementary data set of Lehti-Shiu and Shiu ${ }^{49}$.

\section{D modelling}

The 3D protein structure model was constructed with the program Phyre ${ }^{44}$ (http://www.sbg.bio.ic.ac.uk/ phyre2/html/page.cgi?id=index) and visualized with CCP4MG ${ }^{45}$ (version 2.10.11).

\section{Micro-synteny analysis of Sr62}

The Sr62 CDS was used in a BLAST analysis to identify the putative orthologs in $T$. aestivum, T. durum (TRITD1Bv1G020740.1), Ae. tauschii (AET1Gv20143300, and $H$. vulgare (HORVU1Hr1G011730). No clear Sr62 ortholog was detected in T. aestivum but a clear ortholog for $P m 24$ could be identified. The positions of these best hits were used to extract the proximal and distal genes with Gramene ${ }^{50,51}$ (https://www.gramene.org/\#). For rice, $B$. distachyon, maize, and sorghum, the best hit with the putative barley Sr62 ortholog, HORVU1Hr1G011730, was used for the synteny analysis. For Ae. sharonensis, the genes around Sr62 were manually annotated based on the RNA-Seq and full-length cDNA data for accession 1644. 


\section{Data availability}

The datasets generated during and/or analysed during the current study are publicly available as follows. The sequence reads and the genome assembly were deposited in the European Nucleotide Archive (ENA) under project number PRJEB40322 and PRJEB40049, respectively. The AS_1644 RNA-Seq data was deposited at NCBI under project number PRJEB47173 and the transcriptome assembly is available from e!DAL

(https://doi.org/10.5447/ipk/2021/21). The Sr62 gene and transcript sequence was deposited in NCBI Genbank under accession number MZ826707. The scripts used in this analysis have been published on the GitHub repository (https://github.com/steuernb/MutChromSeq). Seeds of wheat cultivar Zahir (DPRM0080), the Zahir-1644 introgression lines $1 \mathrm{~S}^{\text {sh }} \mathrm{S} \cdot 1 \mathrm{~S}^{\text {sh }} \mathrm{L}$ 1BL (DPRM0081) and $1 S^{\text {sh }} \mathrm{S} \cdot 1 \mathrm{~S}^{\text {sh }} \mathrm{L}-1 \mathrm{DL}$ (DPRM0092), six of the EMS-induced mutants (DPRM0082, DPRM0083, DPRM0084, DPRM0085, DPRM0086, DPRM0087), Ae. sharonensis accession 1644 (DPRM0088) and the three transgenic lines (DPRM0089, DPRM0090, DPRM0091) are available from the Germplasm Resources Unit, John Innes Centre, Norwich, UK (https://www.jic.ac.uk/research-impact/germplasm-resource-unit/). The binary plasmid pGGG-Sr1644-1Sh (Sr62) is available from Addgene under accession number 164087.

\section{Acknowledgements}

We are grateful to the Harold and Adele Lieberman Germplasm Bank (Tel Aviv University), Hazera Seeds Ltd and Limagrain for making germplasm available. We thank Ryan Johnson for phenotyping some of the Sr62 introgression line mutants, JIC Horticultural Services for plant husbandry, Matthew Heaton for assistance with figure design, Manuela Knauft and Ines Walde for technical assistance on Hi-C library preparation and sequencing, Anne Fiebig for sequence data submission, Jan Vrána, Zdeňka Dubská and Romana Šperková for assistance with chromosome sorting and DNA amplification, Bob Mclntosh for review of the draft manuscript, and Willem Boshoff for helpful discussion. This research was supported by the NBI Computing Infrastructure for Science (CiS) group and financed by grants from the 2Blades Foundation, USA, to BJS and BBHW; the Biotechnology and Biological Sciences Research Council (BBSRC) Designing Future Wheat Cross-Institute Strategic Programme to BBHW (BBS/E/J/000PR9780); the Lieberman-Okinow Endowment at the University of Minnesota to BJS; Human Frontier Science Program long-term fellowship (LT000218/2011L) to MJM; the Gordon and Betty Moore Foundation through grant GBMF4725 to the Two Blades Foundation; and the Gatsby Charitable Foundation to JDGJ.

\section{Author contributions}

Extracted DNA for whole-genome shotgun sequencing and long mate-pair libraries: GY. Performed 10X Chromium sequencing: AMD, JE, CP; performed Hi-C sequencing: $\mathrm{AH}$, NS. Performed chromosome flow sorting and amplification: KM, MI, JD. Assembled the Ae. sharonensis genome: MM; conducted BUSCO analysis: MJ. Rough-mapped Sr62: GY, NC, MJM, IHP, JS, PO; fine-mapped Sr62: GY, OM. Generated Zahir-1644: EM. Generated the mutant population: GY; screened for mutants: CW, BJS; genotyped mutants: JP, BS, SW; developed the formula and calculated the minimum number of mutants required for gene identification: GY. Extracted RNA for AS_1644 annotation and MutRNA-Seq: GY. Performed bioinformatics analyses to identify Sr62 and determined its gene structure: GY. Engineered the binary construct: GY; developed the binary vector: MS; transformed it into wheat: $\mathrm{SH}$, WH; phenotyped the transgenic lines: GY, OM, NK, MR, BJS, MP, AJ. Performed phylogenetics, synteny and 3D modelling analyses: GY, MB. Provided scientific support: CG, YY, RA. Conceived study: BW, BJS, JJ, AS, EW, TLR; drafted manuscript: GY, BW. All 
co-authors read and approved the final manuscript. Authors are grouped by institution in the author list, except for the first four and last four authors.

\section{Competing interests}

GY and BBHW are inventors on a patent application, which is based on part of the work presented here. TLR and ERW were employed by the 2Blades Foundation, and ERW continues to serve on the 2Blades board. Both were involved in the conceptualization and design of the research presented, which was cofunded by the 2Blades Foundation. 


\section{References}

1. Peterson, P.D. Stem rust of wheat: from ancient enemy to modern foe. Am. Phytopathol. Soc. (APS Press, St. Paul, 2001).

2. Le Roux, J., \& F. H. Rijkenberg, F.H. Occurrence and pathogenicity of Puccinia graminis f. sp. tritici in South Africa during the period 1981-1985. Phytophylactica 19, 467-472 (1987).

3. Addai, D., Hafi, A., Randall, L., Tennant, P., Arthur, T., Gomboso J. Potential economic impacts of the wheat stem rust strain Ug99 in Australia, ABARES research report, prepared for the Plant Biosecurity Branch, Department of Agriculture and Water Resources, Canberra, September 2018.

4. Pretorius, Z.A., Singh, R.P., Wagoire, W.W., Payne, T.S. Detection of virulence to wheat stem rust resistance gene Sr31 in Puccinia graminis f. sp. tritici in Uganda. Plant Dis 84, 203 (2000).

5. Jin, Y., Szabo, L.J., Pretorius, Z.A., Singh, R.P., Ward, R., Fetch, T. Jr Detection of virulence to resistance gene Sr24 within race TTKS of Puccinia graminis f. sp. tritici. Plant Dis 92, 923-926 (2008).

6. Jin, Y., Szabo, L.J., Rouse, M.N., Fetch, T. Jr, Pretorius, Z.A., Wanyera, R., Njau, P. Detection of virulence to resistance gene Sr36 within the TTKS race lineage of Puccinia graminis f. sp. tritici. Plant Dis 93, 367-370 (2009).

7. Olivera, P. et al. Phenotypic and genotypic characterization of race TKTTF of Puccinia graminis $\mathrm{f}$. sp. tritici that caused a wheat stem rust epidemic in southern Ethiopia in 201314. Phytopathology 105, 917-928 (2015).

8. Olivera Firpo, P.D., Newcomb, M., Flath, K., Sommerfeldt-Impe, N., Szabo, L.J., Carter, M., Luster, D.G. and Jin, Y., Characterization of Puccinia graminis f. sp. tritici isolates derived from an unusual wheat stem rust outbreak in Germany in 2013. Plant Pathol 66, 1258-1266 (2017).

9. Lewis, C.M., Persoons, A., Bebber, D.P. et al. Potential for re-emergence of wheat stem rust in the United Kingdom. Commun Biol 1, 13 (2018).

10. Bhattacharya, S. Deadly new wheat disease threatens Europe's crops. Nature $542,145-$ 146 (2017).

11. Shamanin, V., Salina, E., Wanyera, R., Zelenskiy, Y., Olivera, P., \& Morgounov, A. (2016). Genetic diversity of spring wheat from Kazakhstan and Russia for resistance to stem rust Ug99. Euphytica 212, 287-296.

12. Prank, M., Kenaley, S.C., Bergstrom, G.C., Acevedo, M., Mahowald, N.M. Climate change impacts the spread potential of wheat stem rust, a significant crop disease. Environmental Research Letters 14, (2019).

13. Hafeez, A.N., Arora, S., Ghosh, S., Gilbert, D., Bowden, R.L., and Wulff, B.B.H. Creation and judicious application of a wheat resistance gene atlas. Mol Plant 14, 1053-1070 (2021).

14. Moore, J.W., Herrera-Foessel, S., Lan, C.X., Schnippenkoetter, W., Ayliffe, M., HuertaEspino, J., Lillemo, M., Viccars, L., Milne, R., Periyannan, S. et al. A recently evolved hexose transporter variant confers resistance to multiple pathogens in wheat. Nature Genetics 47, 1494-1498 (2015).

15. Krattinger, S.G., Lagudah, E.S., Spielmeyer, W., Singh, R.P., HuertaEspino, J., McFadden, H., Bossolini, E., Selter, L.L., Keller, B. A putative ABC transporter confers durable resistance to multiple fungal pathogens in wheat. Science 323, 1360-1363 (2009).

16. Zhang, W., Chen, S., Abate, Z., Nirmala, J., Rouse, M.N., Dubcovsky, J. Identification and characterization of $\mathrm{Sr} 13$, a tetraploid wheat gene that confers resistance to the Ug99 stem rust race group. Proceedings of the National Academy of Sciences, 114, E9483E9492 (2017). 
17. Chen, S., Zhang, W, Bolus, S., Rouse, M.N., Dubcovsky, J. Identification and characterization of wheat stem rust resistance gene Sr21 effective against the Ug99 race group at high temperature. PLoS Genetics 14(4): e1007287 (2018)

18. Steuernagel, B., Periyannan, S.K., Hernandez-Pinzon, I., Witek, K., Rouse, M.N., Yu, G., Hatta, A., Ayliffe, M., Bariana, H., Jones, J.D. et al. Rapid cloning of disease-resistance genes in plants using mutagenesis and sequence capture. Nat Biotechnol 34, 652-655 (2016).

19. Zhang, J., Hewitt, T.C., Boshoff, W.H.P. et al. A recombined Sr26 and Sr61 disease resistance gene stack in wheat encodes unrelated NLR genes. Nat Commun 12, 3378 (2021).

20. Periyannan, S., Moore, J., Ayliffe, M., Bansal, U., Wang, X., Huang, L., Deal, K., Luo, M.C., Kong, X., Bariana, H. et al. The gene Sr33, an ortholog of barley Mla genes, encodes resistance to wheat stem rust race Ug99. Science 341, 786-789 (2013).

21. Saintenac, C., Zhang, W., Salcedo, A., Rousse, M., Trick, H., Akhunov, E., Dubcovsky, J. Identification of wheat gene Sr35 that confers resistance to Ug99 stem rust race group. Science 341, 783-786 (2013).

22. Arora, S. et al. Resistance gene cloning from a wild crop relative by sequence capture and association genetics. Nat Biotechnol 37, 139-143 (2019).

23. Mago, R., Zhang, P., Vautrin, S., Simkova, H., Bansal, U., Luo, M-C., Rouse, M., Karaoglu, H., Periyannan, S., Kolmer, J. The wheat Sr50 gene reveals rich diversity at a cereal disease resistance locus. Nature Plants 1, 15186 (2015).

24. Chen, S. et al. Wheat gene Sr60 encodes a protein with two putative kinase domains that confers resistance to stem rust. New Phytol. 225, 948-959 (2020).

25. Gaurav, K., Arora, S., Silva, P. et al. Population genomic analysis of Aegilops tauschiii dentifies targets for bread wheat improvement. Nat Biotechnol (2021).

26. Klymiuk V, Coaker G, Fahima T, Pozniak C. Tandem protein kinases emerge as new regulators of plant immunity. Mol Plant Microbe Interact. 2021 Jun 7. doi: 10.1094/MPMI03-21-0073-CR. Epub ahead of print. PMID: 34096764.

27. Brueggeman, $R$. et al. The barley stem rust-resistance gene Rpg1 is a novel diseaseresistance gene with homology to receptor kinases. Proc. Natl Acad. Sci. USA 99, 93289333 (2002).

28. Klymiuk, V. et al. Cloning of the wheat Yr15 resistance gene sheds light on the plant tandem kinase-pseudokinase family. Nat Commun 9, 3735 (2018).

29. Lu, P., Guo, L., Wang, Z. et al. A rare gain of function mutation in a wheat tandem kinase confers resistance to powdery mildew. Nat Commun 11, 680 (2020).

30. Olivera P.D., \& Steffenson B.J. Aegilops sharonensis: Origin, genetics, diversity, and potential for wheat improvement. Botany 87: 740-756 (2009).

31. Olivera, P. D., Anikster, Y., Kolmer, J. A., and Steffenson, B. J. Resistance of Sharon goatgrass (Aegilops sharonensis) to fungal diseases of wheat. Plant Dis. 91, 942-950 (2007).

32. Scott J. C., Manisterski J., Sela H., Ben-Yehuda P., Steffenson B. J. Resistance of Aegilops species from Israel to widely virulent African and Israeli races of the wheat stem rust pathogen. Plant Dis 98 1309-1320 (2014).

33. Tsujimoto H., Tsunewaki K. Gametocidal genes in wheat and its relatives. I. Genetic analyses in common wheat of a gametocidal gene derived from Aegilops speltoides. Canadian Journal of Genetics and Cytology 26:78-84 (1984).

34. Marais, G.F., McCallum, B. \& Marais, A.S. Leaf Rust and Stripe Rust Resistance Genes Derived from Aegilops Sharonensis. Euphytica 149, 373-380 (2006).

35. Knight, E., Binnie, A., Draeger, T., Moscou, M., Rey, M. D., Sucher, J., Mehra, S., King, I., \& Moore, G. Mapping the 'breaker' element of the gametocidal locus proximal to a block of sub-telomeric heterochromatin on the long arm of chromosome $4 \mathrm{~S}^{\text {sh }}$ of Aegilops sharonensis. Theoretical and Applied Genetics 128(6), 1049-1059 (2015).

36. Millet E., Manisterski J., Ben-Yehuda P., Distelfeld A., Deek J., Wan A., Chen X., Steffenson B.J. Introgression of leaf rust and stripe rust resistance from Sharon goatgrass 
(Aegilops sharonensis Eig) into bread wheat (Triticum aestivum L.). Genome 57:309-316 (2014).

37. Millet, E., Steffenson, B. J., Prins, R., Sela, H., Przewieslik-Allen, A. M., and Pretorius, Z. A. Genome targeted introgression of resistance to African stem rust from Aegilops sharonensis into bread wheat. Plant Genome 10, 1-11 (2017).

38. $\mathrm{Yu}, \mathrm{G}$. et al. Discovery and characterization of two new stem rust resistance genes in Aegilops sharonensis. Theor. Appl. Genet. 130, 1207-1222 (2017).

39. Monat, C., Padmarasu, S., Lux, T. et al. TRITEX: chromosome-scale sequence assembly of Triticeae genomes with open-source tools. Genome Biol 20, 284 (2019).

40. International Wheat Genome Sequencing Consortium (IWGSC). Shifting the limits in wheat research and breeding using a fully annotated reference genome. Science 361 , issue 6403 (2018).

41. Elshire, R.J., Glaubitz, J.C., Sun, Q., Poland, J.A., Kawamoto, K., Buckler, E.S., et al. A robust, simple genotyping-by-sequencing (GBS) approach for high diversity species. PLoS ONE 6(5): e19379 (2011).

42. Uauy, C., Wulff, B.B.H., Dubcovsky, J. Combining traditional mutagenesis with wew high-throughput sequencing and genome editing to reveal hidden variation in polyploid wheat. Annu Rev Genet. 51, 435-454 (2017).

43. Steuernagel B, Witek K, Krattinger SG, Ramirez-Gonzalez RH, Schoonbeek HJ, Yu G, Baggs E, Witek AI, Yadav I, Krasileva KV, Jones JDG, Uauy C, Keller B, Ridout CJ, Wulff $\mathrm{BBH}$. The NLR-Annotator tool enables annotation of the intracellular immune receptor repertoire. Plant Physiol 183, 468-482 (2020).

44. Kelley, L., Mezulis, S., Yates, C. et al. The Phyre2 web portal for protein modelling, prediction and analysis. Nat Protoc 10, 845-858 (2015).

45. McNicholas, S., Potterton, E., Wilson, K.S. and Noble, M.E.M. Presenting your structures: the CCP4mg molecular-graphics software. Acta Cryst. D67, 386-394 (2011).

46. Holliday, G.L., Mitchell, J.B., Thornton, J.M. Understanding the functional roles of amino acid residues in enzyme catalysis. J Mol Biol 390, 560-577 (2009).

47. Hanks, S.K., Quinn, A. M. \& Hunter, T. The protein kinase family: conserved features and deduced phylogeny of the catalytic domains. Science 241, 42-52 (1988).

48. Needleman, S.B. \& Wunsch, C.D. A general method applicable to the search for similarities in the amino acid sequence of two proteins. J Mol Biol 48, 443-53 (1970).

49. Lehti-Shiu, M.D. \& Shiu, S-H. Diversity, classification and function of the plant protein kinase superfamily. Phil Trans R Soc B, 367, 2619-2639 (2012).

50. Tello-Ruiz, M.K., Naithani, S., Gupta, P., Olson, A., Wei, S., Preece, J., Jiao, Y., Wang, B., Chougule, K., Garg, P., Elser, J., Kumari, S., Kumar, V., Contreras-Moreira, B., Naamati, G., George, N., Cook, J., Bolser, D.M., D'Eustachio, P., Stein, L.D., Gupta, A., Xu, W., Regala, J., Papatheodorou, I., Kersey, P.J., Flicek, P., Taylor, C., Jaiswal, P., Ware, D. Gramene 2021: Harnessing the power of comparative genomics and pathways for plant research. Nucleic Acids Res 49(D1): D1452-D1463 (2021).

51. Howe, K.L., Contreras-Moreira, B., De Silva. N., et al. Ensembl Genomes 2020enabling non-vertebrate genomic research, Nucleic Acids Research 48, Issue D1, D689D695 (2020).

52. Chalupska, D., Lee, H.Y., Faris, J.D., Evrard, A., Chalhoub, B., Haselkorn, R., Gornicki, P. Acc homoeoloci and the evolution of wheat genomes. Proceedings of the National Academy of Sciences USA 105, 9691-9696 (2008).

53. Kourelis, J., \& van der Hoorn, R.A.L. Defended to the Nines: 25 Years of resistance gene cloning identifies nine mechanisms for $R$ protein function. Plant Cell 30, 285-299 (2018).

54. Van der Biezen, E.A., \& Jones, J.D.G. Plant disease- resistance proteins and the genefor-gene concept. Trends Plant Sci. 23, 454-456 (1998).

55. Jones, J.D.G., \& Dangl, J.L. The plant immune system. Nature 444, 323-329 (2006).

56. DeYoung, B.J., \& Innes, R.W. Plant NBS-LRR proteins in pathogen sensing and host defense. Nat Immunol, 7, 1243-1249 (2006). 
57. Cesari, S. Multiple strategies for pathogen perception by plant immune receptors. New Phytol. 219, 17-24 (2018).

58. van Wersch, S., Tian, L., Hoy, R., and Li, X. Plant NLRs: the whistleblowers of plant immunity. Plant Commun. 1, 100016 (2020).

59. van der Hoorn, R.A., Kamoun, S. From guard to decoy: a new model for perception of plant pathogen effectors. Plant Cell. 20, 2009-2017 (2008).

60. Mackey, D., Holt, B.F. 3rd, Wiig, A., Dangl, J.L. RIN4 interacts with Pseudomonas syringae type III effector molecules and is required for RPM1-mediated resistance in Arabidopsis. Cell 108, 743-54 (2002).

61. Kim, M.G., da Cunha, L., McFall, A.J., Belkhadir, Y., DebRoy, S., Dangl, J.L., and Mackey, D. (2005). Two Pseudomonas syringae type III effectors inhibit RIN4-regulated basal defense in Arabidopsis. Cell 121, 749-759.

62. Hofius, D., Schultz-Larsen, T., Joensen, J., Tsitsigiannis, D.I., Petersen, N.H., Mattsson, O., Jørgensen, L.B., Jones, J.D., Mundy., J., Petersen, M. Autophagic components contribute to hypersensitive cell death in Arabidopsis. Cell 137, 773-783 (2009).

63. Wu, A.J., Andriotis, V.M., Durrant, M.C., Rathjen, J.P. A patch of surface-exposed residues mediates negative regulation of immune signalling by tomato Pto kinase. Plant Cell 16, 2809-2821 (2004).

64. Mucyn, T.S., Clemente, A., Andriotis, V.M.E., Balmuth, A.L., Oldroyd, G.E.D., Staskawicz, B.J., and Rathjen, J.P. The tomato NBARC-LRR protein Prf interacts with Pto kinase in vivo to regulate specific plant immunity. Plant Cell 18, 2792-2806 (2006)

65. Martin, G.B., Brommonschenkel, S.H., Chunwongse, J., Frary, A., Ganal, M.W., Spivey, R., Wu, T., Earle, E.D., Tanksley, S.D. Map-based cloning of a protein kinase gene conferring disease resistance in tomato. Science 262, 1432-1435 (1993)

66. Wang, G., Roux, B., Feng, F., Guy, E., Li, L., Li, N., Zhang, X., Lautier, M., Jardinaud, M.F., Chabannes, M., Arlat, M., Chen, S., He, C., Noël, L.D., Zhou, J.M. The decoy substrate of a pathogen effector and a pseudokinase specify pathogen-induced modifiedself recognition and immunity in plants. Cell Host Microbe 18, 285-295 (2015).

67. Lehti-Shiu, M.D., Zou, C., Hanada, K., Shiu, S.H. Evolutionary history and stress regulation of plant receptor-like kinase/Pelle genes, Plant Phys 150, 12-26 (2009).

68. Mascher, M., Gundlach, H., Himmelbach, A., et al. A chromosome conformation capture ordered sequence of the barley genome. Nature 544, 427-433 (2017).

69. Luo, M.C., Gu, Y., Puiu, D. et al. Genome sequence of the progenitor of the wheat D genome Aegilops tauschii. Nature 551, 498-502 (2017).

70. Maccaferri, M., Harris, N.S., Twardziok, S.O. et al. Durum wheat genome highlights past domestication signatures and future improvement targets. Nat Genet 51, 885-895 (2019).

71. Ouyang, S., Zhu, W., Hamilton, J., Lin, H., Campbell, M., Childs, K., Buell, C. R. The TIGR rice genome annotation resource: improvements and new features. Nucleic Acids Research, 35 (Database issue), D883-D887 (2007).

72. Beier, S., Himmelbach, A., Colmsee, C. et al. Construction of a map-based reference genome sequence for barley, Hordeum vulgare L. Sci Data 4, 170044 (2017).

73. Eilam, T., Anikster, Y., Millet, E., Manisterski, J., Sagi-Assif, O., and Feldman, M. Genome size and genome evolution in diploid Triticeae species. Genome, 50, 1029-1037 (2007).

74. International Barley Genome Sequencing Consortium (IBGSC). A physical, genetic and functional sequence assembly of the barley genome. Nature 491, 711-716 (2012).

75. Ling, H.Q., Ma, B., Shi, X. et al. Genome sequence of the progenitor of wheat A subgenome Triticum urartu. Nature 557, 424-428 (2018).

76. Marcussen, T., Sandve, S.R., Heier, L., Spannagl, M., Pfeifer, M., International Wheat Genome Sequencing Consortium, Jakobsen, K.S., Wulff, B.B., Steuernagel, B., Mayer, K.F., Olsen, O.A. Ancient hybridizations among the ancestral genomes of bread wheat. Science 18, 6194 (2014).

77. Miki, Y., Yoshida, K., Mizuno, N., Nasuda, S., Sato, K., Takumi, S. Origin of wheat Bgenome chromosomes inferred from RNA sequencing analysis of leaf transcripts from section Sitopsis species of Aegilops. DNA Res 26, 171-182 (2019). 
78. Avni, R., et al. Phylogenentic relationships and genetic resources for wheat improvement revealed by genome sequence of three Aegilops species of section Sitopsis. bioRxiv. doi.org/10.1101/2021.08.09.455628 (2021).

79. Tsujimoto, H. Gametocidal genes in wheat and its relatives. IV. Functional relationships between six gametocidal genes. Genome 38, 283-289 (1995).

80. Friebe, B., Zhang, P., Gill, B.S. et al. Characterization of a knock-out mutation at the Gc2 locus in wheat. Chromosoma 111, 509-517 (2003).

81. Grewal, S., Gardiner, L.-J., Ndreca, B., Knight, E., Moore, G., King, I.P. and King, J. Comparative mapping and targeted-capture sequencing of the gametocidal loci in Aegilops sharonensis. The Plant Genome, 10, 2 (2017).

82. Sánchez-Martín, J., Steuernagel, B., Ghosh, S., Herren, G., Hurni, S., Adamski, N., Vrána , J., Kubaláková, M., Krattinger, S.G., Wicker, T., Doležel, J., Keller, B., Wulff, B.B. Rapid gene isolation in barley and wheat by mutant chromosome sequencing. Genome Biol 17, 221 (2016).

83. Dracatos, P.M., Bartoi, J., Elmansour H, et al. The coiled-coil NLR Rph1, confers leaf rust resistance in barley cultivar Sudan. Plant Physiol 179, 1362-1372 (2019).

84. Thind, A.K., Wicker, T., Šimková, H., Fossati, D., Moullet, O., Brabant, C., Vrána, J., Doležel, J., Krattinger, S.G. Rapid cloning of genes in hexaploid wheat using cultivarspecific long-range chromosome assembly. Nat Biotechnol. 35, 793-796 (2017).

85. Xing, L., Hu, P., Liu, J., Witek, K., Zhou, S., Xu, J., Zhou, W., Gao, L., Huang, Z., Zhang, R., Wang, X., Chen, P., Wang, H., Jones, J.D.G., Karafiátová, M., Vrána, J., Bartoš, J., Doležel, J., Tian, Y., Wu, Y., Cao, A. Pm21 from Haynaldia villosa encodes a CC-NBSLRR protein conferring powdery mildew resistance in wheat. Mol Plant 4, 11, 874-878 (2018).

86. Wulff, B.B.H., \& Dhugga, K.S. Wheat-the cereal abandoned by GM. Science 361, 451452 (2018).

87. Argentina first to market with drought-resistant GM wheat. Nat Biotechnol 39, 652 (2021).

88. Crop Solutions Announces Regulatory Approval of Drought Tolerant HB4® Wheat by Brazil's CTNBio, https://www.businesswire.com/news/home/20211111006003/en/Bioceres-Crop-SolutionsAnnounces-Regulatory-Approval-of-Drought-Tolerant-HB4\%C2\%AE-Wheat-byBrazil\%E2\%80\%99s-CTNBio, accessed on 26/11/2021

89. Stakman, E. C. Barberry eradication prevents black rust in Western Europe. United States Department of Agriculture, Department Circular 269, 1-15 (1923).

90. Yu, G., Hatta, A., Periyannan, S., Lagudah, E., Wulff, B.B.H. Isolation of wheat genomic DNA for gene mapping and cloning. Methods Mol Biol 1659:207-213 (2017).

91. Jupe, F., Rivkin, A.C., Michael, T.P., Zander, M., Motley, S.T., Sandoval, J.P. et al. The complex architecture and epigenomic impact of plant T-DNA insertions https://doi.org/10.1371/journal.pgen.1007819 (2019)

92. Vrána, J., M. Kubaláková, H. Šimková, J. Cíhalíková, M.A. Lysák, and J. Doležel. Flow sorting of mitotic chromosomes in common wheat (Triticum aestivum L.). Genetics 156, 2033-2041 (2000).

93. Kubaláková, M., P. Kovářová, P. Suchánková, J. Číhalíková, J. Bartoš, S. Lucretti, N. Watanabe, S.F. Kianian, and J. Doležel. Chromosome sorting in tetraploid wheat and its potential for genome analysis. Genetics 170, 823-829 (2005).

94. Kubaláková, M., J. Macas \& Doležel, J. Mapping of repeated DNA sequences in plant chromosomes by PRINS and C-PRINS. Theor Appl Genet 94, 758-763 (1997).

95. Molnár, I., Vrána, J., Burešová, V., Cápal, P., Farkas, A., Darkó, É., Cseh, A., Kubaláková, M., Molnár-Láng, M., Doležel, J. Dissecting the $U, M, S$ and $C$ genomes of wild relatives of bread wheat (Aegilops spp.) into chromosomes and exploring their synteny with wheat. The Plant Journal, 88, 452-467 (2016).

96. Zhang, Y., Zhu, M.-L. and Dai, S.-L. Analysis of karyotype diversity of 40 Chinese chrysanthemum cultivars. J Sytematics Evolution, 51, 335-352 (2013). 
97. Badaeva, E.D., Friebe, B., Gill, B.S. Genome differentiation in Aegilops. 1. Distribution of highly repetitive DNA sequences on chromosomes of diploid species. Genome 39, 293306 (1996).

98. Šimková, H., Svensson, J.T., Condamine, P., Hřibová, E., Suchánková, P., Bhat, P. R., Bartoš, J., Šafář, J., Close, T.J., Doležel, J. Coupling amplified DNA from flow-sorted chromosomes to high-density SNP mapping in barley. BMC Genomics 9, 294 (2008).

99. Bushnell, B., Rood, J., Singer, E. BBMerge - Accurate paired shotgun read merging via overlap. PLOS ONE 12: e0185056 (2017).

100. Li, H. BFC: correcting Illumina sequencing errors. Bioinformatics 31: 2885-2887 (2015)

101. Chikhi R., Limasset A., Medvedev P. Compacting de Bruijn graphs from sequencing data quickly and in low memory. Bioinformatics 32, i201-i208 (2016).

102. Luo, R., Liu, B., Xie, Y., Li, Z., Huang, W., Yuan, J., He, G., Chen, Y., Pan, Q., Liu, Y. SOAPdenovo2: an empirically improved memory-efficient short-read de novo assembler. Gigascience 1, 18 (2012).

103. Chapman, J.A., Mascher, M., Buluc, A., Barry, K., Georganas, E., Session, A., Strnadova, V., Jenkins, J., Sehgal, S., Oliker, L., Schmutz, J., Yelick, K.A., Scholz, U., Waugh, R., Poland, J.A., Muehlbauer, G.J., Stein, N, Rokhsar, D.S. A whole-genome shotgun approach for assembling and anchoring the hexaploid bread wheat genome. Genome Biol 16, 26 (2015).

104. Mascher, M., Richmond, T.A., Gerhardt, D.J., Himmelbach, A., Clissold, L., Sampath, D., Ayling, S., Steuernagel, B., Pfeifer, M., D’Ascenzo, M., Akhunov, E.D., Hedley, P.E., Gonzales, A.M., Morrell, P.L., Kilian, B., Blattner, F.R., Scholz, U., Mayer, K.F., Flavell, A.J., Muehlbauer, G.J., Waugh, R., Jeddeloh, J.A. and Stein, N. Barley whole exome capture: a tool for genomic research in the genus Hordeum and beyond. Plant J 76, 494505 (2013).

105. Muñoz-Amatriaín M. et al. An improved consensus linkage map of barley based on flow-sorted chromosomes and single nucleotide polymorphism markers. The Plant Genome 4:238-249 (2011).

106. Kim, D., Paggi, J.M., Park, C., Bennett, C., Salzberg, S.L. Graph-based genome alignment and genotyping with HISAT2 and HISAT-genotype. Nat Biotechnol 37, 907-915 (2019).

107. Li, H., Handsaker, B., Wysoker, A., Fennell, T., Ruan, J., Homer, N., Marth, G., Abecasis, G., Durbin, R., 1000 Genome Project Data Processing Subgroup, The Sequence alignment/map (SAM) format and SAMtools, Bioinformatics 25(16) 2078-9 (2009).

108. Poland, J.A., \& Rife, T.W. Genotyping-by-sequencing for plant breeding and genetics. Plant Genome 5, 92-102 (2012).

109. Li, H. \& Durbin, R. Fast and accurate short read alignment with Burrows-Wheeler Transform. Bioinformatics 25, 1754-60 (2009).

110. Sim, N.L., Kumar, P., Hu J., Henikoff, S., Schneider, G., Ng, P.C. SIFT web server: predicting effects of amino acid substitutions on proteins. Nucleic Acids Res 40, W452W457 (2012).

111. Wypij, D. (2014). Binomial Distribution. In Wiley StatsRef: Statistics Reference Online (eds N. Balakrishnan, T. Colton, B. Everitt, W. Piegorsch, F. Ruggeri and J.L. Teugels). https://doi.org/10.1002/9781118445112.stat04852

112. Hayta, S., Smedley, M.A., Demir, S.U. et al. An efficient and reproducible Agrobacterium-mediated transformation method for hexaploid wheat (Triticum aestivum L.). Plant Methods 15, 121 (2019).

113. Bartlett, J.G., Alves, S.C., Smedley, M. et al. High-throughput Agrobacterium-mediated barley transformation. Plant Methods 4, 22 (2008). 


\section{Supplementary Files}

This is a list of supplementary files associated with this preprint. Click to download.

- Sr62SupplementaryFiles.pdf

- SuppTable5.xlsx

- SuppTable9.xlsx

- SuppTable5.xlsx

- SupplementaryFile1.pdb 